Rev Bras Fisiol Exerc 2021;20(4):S1-S36

doi: $10.33233 /$ rbfex.v20i4.4914

\title{
Simpósio de Bioquímica do Exercício em Saúde
}

\author{
Pontifícia Universidade Católica do Paraná
}

Curitiba, 23 a 25 de junho de 2021

\section{Coordenador geral: Prof. Dr. Ricardo Aurino Pinho}

rapinho12@gmail.com

\author{
Palestrantes \\ Dr. Rolando B. Ceddia, York University - Toronto, Canadá \\ Dr. José Alberto R. Duarte, Universidade do Porto, Portugal \\ Dr. Rafael Deminice, UEL \\ Dr. Fábio S. Lira, UNESP \\ Dra. Alessandra Peres, UFCSPA \\ Dr. José Cesar R. Neto, USP \\ Dra. Patrícia C. Brum, USP \\ Dr. Leonardo R. Silveira, Unicamp \\ Dr. Ricardo A. Pinho, PUCPR \\ Dr. Luiz Fernando Freire Royes, UFSM \\ Dr. Aderbal S. Aguiar, UFSC \\ Dr. Ricardo Arida, Unifesp \\ Dra. Claudia R. Cavaglieri, Unicamp \\ Dr. Fernando Tadeu T. Frajacomo, Univ. Estácio de Sá \\ Dra. Renata L. Bertin, UFPR \\ Dra. Rochelle R. Costa, UFRGS \\ Dra. Luciele G. Minuzzi, UNESP
}

\section{Equipe de apoio científico}

Dr. Eduardo dal Bosco Brunetti Cunha, PUCPR: edubrunetti@hotmail.com

Ddo. Amanda Kruger Costa, PUCPR: amandakruger91@gmail.com

Ddo. Simone Galbiati Terçariol, PUCPR- simone.galbiati@uol.com.br

Ddo. Christiano Francisco dos Santos, PUCPR: christiano.francisco73@gmail.com

Ddo. André Domingos Lass, PUCPR: andrelass0974@gmail.com

Ddo. Paulo André Bispo Machado, PUCPR: paulo_vicmar@hotmail.com

Dda. Ana Carolina Gadotti, PUCPR: ana_raixu3@hotmail.com

\section{Equipe de apoio administrativo e de gestão}

Jane Fabia Domenica Pulowski, PUCPR

Paula Maira Portela do Nascimento, PPGCS-PUCPR

Andréia Bogo Betiati, MKT-PUCPR 


\section{Editorial}

O exercício físico tem sido considerado como um dos mais indispensáveis aspectos do comportamento humano na prevenção e tratamento de doenças por induzir diferentes estímulos que alteram positivamente o organismo. Essa compreensão é fruto de dezenas de milhares de pesquisas e publicações, ao longo dos anos, pelas quais revelam que praticar exercícios físicos regulares protege o organismo e contribui para a qualidade de vida da população. Nesse cenário, a bioquímica do exercício tem dado expressiva contribuição para esse avanço do conhecimento por ser um dos campos disciplinares que avança na compreensão do papel do exercício físico sobre mecanismos celulares e moleculares da saúde/doença humana. Os resultados obtidos pelos pesquisadores, nesse campo de conhecimento, são timidamente conhecidos pela comunidade acadêmica e científica, e por isso, promover estratégias que disseminam e popularize os avanços científicos são necessários.

A realização de eventos científicos que congreguem cientistas, estudantes de graduação e pós-graduação de diversas áreas do conhecimento promove interações entre diferentes campos do saber, bem como, auxilia na disseminação dos avanços científicos dentro dessa área de investigação. Isto permite disseminar as descobertas geradas no âmbito científico bem como possibilita a reflexão, discussão e contribuição dos pares em torno do tema proposto. Foi com essa perspectiva que o Laboratório de Bioquímica do Exercício em Saúde vinculado ao Programa de Pós-graduação em Ciências da Saúde da Escola de medicina da Pontifícia Universidade Católica do Paraná promoveu remotamente, entre os dias 23 e 25 de junho de 2021, a segunda edição do Simpósio de Bioquímica do Exercício em Saúde. Foi um evento de com abrangência nacional tendo a bioquímica do exercício físico como foco central e teve a contribuição de 17 cientistas de expressivo reconhecimento de 15 instituições nacionais e duas estrangeiras. Foram 622 inscritos de 116 instituições representando 18 estados brasileiros, além de Portugal e Canadá que participaram de atividades interativas com efetiva aproximação com os pesquisadores-palestrantes, como segue: 4 workshops, 6 conferências e 2 painéis, 30 resumos apresentados remotamente, duas sessões ao vivo de tema livres e duas sessões de apresentação de projetos de dissertações e teses.

O resultado deste evento foi exitoso o que pode ser observado nas inúmeras manifestações feitas pelos participantes durante a transmissão do evento tanto quanto nas avaliações obtidas por instrumento específico após o evento. O sucesso dessa edição aponta para novas edições nos anos seguintes. 
Nas páginas seguintes, você poderá ler os resumos de trabalhos recentes desenvolvidos por diferentes centros de pesquisa os quais foram submetidos e apresentados por alunos de iniciação científica, mestrado, doutorado e pós-doutorado, contribuindo para a qualidade do Simpósio e a disseminação do conhecimento científico em Bioquímica do Exercício.

Prof. Dr. Ricardo A. Pinho

Coordenador geral do Simpósio de Bioquímica do Exercício em Saúde

\section{I - Resumos de trabalhos completos}

\section{Efeito agudo de uma série de agachamento com fita de suspensão sobre variáveis hemodinâmicas}

Souza JCA ${ }^{1 *}$, Teixeira JAA ${ }^{1}$, Teixeira $\mathrm{KKL}^{1}$, Santos Júnior $\mathrm{VM}^{2}$, Rodrigues $\mathrm{CNS}^{1}$, Duarte $\mathrm{ACGO}^{1}$

${ }^{1}$ Laboratório de Nutrição e Metabolismo aplicados ao Exercício, Universidade Federal de São Carlos, São Carlos, São Paulo, Brasil

${ }^{2}$ Núcleo de Vivências Corporais, Centro Universitário de Votuporanga, Votuporanga, São Paulo, Brasil

*jeancesar.andrade@gmail.com

Introdução: O treinamento funcional, tendo como meio a fita de suspensão, caracterizase pelo uso de fitas ancoradas em pontos fixos, onde os praticantes mantem suspenso mãos ou pés, enquanto o outro par de extremidades permanece no solo. Devido ao aumento do número de praticantes, que apresentam características e níveis de treinamento distintos, torna-se importante investigar as respostas fisiológicas provocadas por esta modalidade de treinamento. Este estudo avaliou o efeito agudo de uma série de agachamento com auxílio da fita de suspensão sobre variáveis hemodinâmicas de indivíduos treinados. Métodos: Trinta voluntários, sendo 15 homens (29,33 $\pm 4,79$ anos), 15 mulheres (26,08 $\pm 4,38$ anos), treinados (> 150 minutos/semana de atividade física), alunos do Centro Universitário de Votuporanga-UNIFEV, tiveram suas variáveis hemodinâmicas: pressão arterial sistólica (PAS), pressão arterial diastólica (PAD) e pressão arterial média (PAM), aferidas em repouso (10 minutos antes), imediatamente após e nos $3^{\circ}, 6^{\circ}, 9^{\circ}$ e $12^{\circ}$ minutos decorridos o término da série. A sessão de treinamento consistiu em: uma série de vinte repetições de agachamento 
com auxílio da fita de suspensão durante 1 minuto. Os dados foram analisados pelo software STATISTIC 7, adotando significância de $p<0,05$. Resultados: Verificou-se 0 aumento significativo das variáveis de PAS em homens $(p=0,03)$ e mulheres $(p=0,03)$ e PAM somente nos homens ( $p=0,04)$ em comparação ao repouso. Tais diferenças não foram observadas em PAD em ambos os sexos (homens $p=0,557$; mulheres $p=$ 0,348 ) e PAM nas mulheres ( $p=0,502$ ). Este aumento não se manteve nos minutos que sucederam a série, com os valores retornando aos parâmetros de repouso. Conclusão: Uma série de agachamento com fita de suspensão promoveu a elevação de variáveis hemodinâmicas imediatamente após o término da série, onde a PAS mostrou ser a variável determinante para a modulação da PAM. Tais dizeres apontam para um aumento da demanda cardiovascular na modalidade.

Palavras-chave: exercício físico; fita de suspensão; pressão arterial; treinamento. Fonte Financiadora: CAPES

\section{Recuperação autonômica cardíaca após esforço máximo em adultos obesos e não obesos}

Schamne, JC ${ }^{1,2 *}$, Araújo AC ${ }^{1}$, Costa $\mathrm{BM}^{1}$, Okuno NM${ }^{1}$

${ }^{1}$ Universidade Estadual de Ponta Grossa, Ponta Grossa, Paraná, Brasil

${ }^{2}$ Universidade Federal do Paraná, Curitiba, Paraná, Brasil

*juliocezarschamne@gmail.com

Introdução: O comportamento da variabilidade da frequência cardíaca (VFC) durante a recuperação após o exercício pode estar prejudicado em indivíduos com excesso de gordura corporal. O objetivo deste estudo foi comparar os índices da VFC entre adultos eutróficos e obesos durante a recuperação pós-exercício. Métodos: Treze homens obesos (OBE) (24,9 \pm 4,4 anos) e 18 homens eutróficos (CON) (23,2 \pm 4,1 anos) realizaram um teste incremental máximo (protocolo de Balke modificado) em uma esteira ergométrica até a exaustão voluntária. Logo após o fim do teste, os indivíduos caminharam na esteira nos primeiros 5 minutos e assumiram a posição sentada nos últimos 5 minutos de recuperação. $O$ tempo de transição entre o fim do exercício e o início da recuperação, bem como o tempo de deslocamento da esteira para a cadeira, foram de aproximadamente 5 segundos. Os batimentos cardíacos foram monitorados continuamente durante o exercício e nos 10 minutos de recuperação pós-exercício, por meio de um cardiofrequencímetro. A raiz quadrada da média do quadrado das diferenças entre intervalos RR adjacentes (RMSSD) e os componentes de baixa e alta frequência (BF e AF, respectivamente) foram os índices da VFC analisados nos últimos 
5 minutos de recuperação pós-exercício. As variáveis foram comparadas entre os grupos por meio do teste $\mathrm{t}$ para amostras independentes. Resultados: Não houve diferença significativa entre os grupos para a BF (OBE: $4,1 \pm 1,1 \mathrm{~ms}^{2}$ vs. CON: $4,5 \pm 1,1$ $\mathrm{ms}^{2} ; \mathrm{p}=0,212$ ). No entanto, o RMSSD (OBE: $4,8 \pm 1,9 \mathrm{~ms}$ vs. CON: 7,6 $\pm 3,9 \mathrm{~ms} ; \mathrm{p}=$ 0,012 ) e a AF (OBE: $1,9 \pm 1,1 \mathrm{~ms}^{2}$ vs. CON: $2,8 \pm 1,3 \mathrm{~ms}^{2}$; $\mathrm{p}=0,039$ ) foram significativamente menores no grupo OBE em comparação ao grupo CON. Conclusão: Adultos obesos possuem uma reativação parassimpática mais lenta após esforço máximo em comparação com adultos eutróficos.

Palavras-chave: obesidade; doenças cardiovasculares; variabilidade da frequência cardíaca; exercício físico

\section{Efeito da periodização do treinamento no risco cardiovascular de adultos com obesidade: um ensaio clínico randomizado}

Streb $A R^{1 *}$, Bertuol $C^{1}$, Rosa $F^{1}$, Del Duca $G^{1}$

${ }^{1}$ Grupo de Estudo e Pesquisa em Exercício Físico e Doenças Crônicas Não Transmissíveis, Universidade Federal de Santa Catarina, Florianópolis, Santa Catarina, Brasil

*anne.streb@posgrad.ufsc.br

Introdução: Permanecem inconclusivos os efeitos dos tipos de periodização do treinamento na redução do risco cardiovascular em adultos com obesidade. Objetivouse verificar o efeito do treinamento combinado não periodizado e com periodização linear no risco cardiovascular em adultos com obesidade. Métodos: Realizou-se um ensaio clínico randomizado, cego e controlado com adultos com obesidade alocados em três grupos: controle (GC), treinamento combinado não periodizado (GN) e treinamento combinado com periodização linear (GP). A intervenção ocorreu por 16 semanas, em três sessões semanais de treinamento combinado (aeróbio e força na mesma sessão). O GN treinou em intensidade moderada durante toda a intervenção (50 a 59\% FCres e 12 a $10 \mathrm{RMs}$ ). O GP progrediu linearmente em intensidade nos três mesociclos (5 semanas), passando por leve (40 a 49\% FCres e 14 a 12 RMs), moderada e, no final, vigorosa (60 a 69\% FCres e 10 a 8 RMs). Utilizou-se o algoritmo de Framingham Risk Score (FRS) para estimativa do risco cardiovascular. Empregou-se Equações de Estimativa Generalizadas estratificada por sexo, considerando $p<0,10$ para a interação grupo*tempo. Resultados: Participaram 27 homens com 34,6 \pm 7,5 anos e 42 mulheres com $34.7 \pm 7,0$ anos. A média de IMC dos participantes foi de 33,5 $\pm 2,8 \mathrm{~kg} / \mathrm{m}^{2}$. Para os homens, houve diferença significativa entre os grupos ao longo do 
tempo $\left(\mathrm{pg}^{*} \mathrm{t}=0,058\right)$ na pontuação do FRS. Ambos os grupos de treinamento apresentaram reduções (GN- pré: $2.78 \pm 0.46$; pós: $0.50 \pm 1.02$; GP- pré: $1.67 \pm 0.52$; pós: $0.25 \pm 0.54$ ). O CG não modificou o FRS ao longo do tempo (pré: $1.38 \pm 0.88$; pós: $2.14 \pm 0.81$; valor $p=0.404$ ). Entre as mulheres, não houve mudanças significativas entre os grupos ao longo do tempo $\left(\mathrm{pg}^{*} \mathrm{t}=0.907\right)$. Conclusão: Dezesseis semanas de treinamento combinado, independentemente do modelo da periodização, reduzem o risco cardiovascular em homens com obesidade.

Palavras-chave: adultos; fatores de risco; manejo da obesidade; exercício

Fonte Financiadora: CAPES

O componente lento no consumo de oxigênio pulmonar: mecanismos fisiológicos que explicam a perda de eficiência metabólica e mecânica durante o ciclismo em diferentes intensidades

Do Nascimento Salvador $\mathrm{PC}^{1,2 *}$, Antunes $\mathrm{D}^{1}$, Nascimento EMF${ }^{1}$, Possamai $\mathrm{LT}^{1}$, Guglielmo LGA ${ }^{1}$, Denadai BS ${ }^{1}$

${ }^{1}$ Universidade Federal de Santa Catarina - UFSC, Florianópolis, Brasil

${ }^{2}$ Centro Universitário Leonardo da Vinci - UNIASSELVI, Indaial, Brasil

*nascimentosalvadorpc@gmail.com

Introdução: Buscou-se verificar os mecanismos fisiológicos centrais e/ou periféricos que explicam o componente lento de consumo de oxigênio $\left(\mathrm{V}^{2} \mathrm{O}_{2 c}\right)$ e a perda de eficiência mecânica durante o ciclismo em diferentes intensidades. Método: Dezesseis homens fisicamente ativos realizaram em dias diferentes a determinação da capacidade muscular oxidativa $\left(\dot{\mathrm{V}} \mathrm{O}_{2 \mathrm{~m}}\right)$, teste máximo de rampa e cargas constantes nos domínios moderado (6 min), pesado (D30) e muito pesado (D60) (12 min). O decréscimo no torque produzido (DT) foi determinado através de sprints isocinéticos com duração de $3 \mathrm{~s}$, no início e no final de cada visita ou a cada dois minutos em duas ocasiões (D30 e D60). Resultados: O $\dot{\mathrm{VO}}_{2 s c}$ foi maior no exercício de $\mathrm{D} 60$ ( $70 \%$ vs. $\sim 28 \%$ do $\dot{\mathrm{VO}}_{2}$ de reserva no D30). Houve diferença significativa na amplitude final da extração muscular de $\mathrm{O} 2$ (HHb) (D60 90\% vs. 82\% no D30 vs. 45\% no moderado; \% da máxima fisiológica) e no DT (D60 $30 \mathrm{Nm}$ vs. D30 8 Nm). O maior DT ocorreu nos primeiros 2 min de exercício (D60 $23 \mathrm{Nm}$; D30 12 Nm). Não foi observada uma relação significativa entre o $\dot{V}_{2 s c}$ e DT. A amplitude final da $\mathrm{HHb}$ explica parcialmente $(r=-0,52)$ o DT inicial (2 min) no D60. O $\dot{V}_{2 m}$ apresentou relação significativa com a Atotal da $\mathrm{HHb}$ (D60 $r=-$ 0,53; D30 $r=-0,64)$. Conclusão: Conclui-se que o $\dot{\mathrm{V}}_{2 s c}$, a necessidade de uma maior extração de $\mathrm{O}_{2}$ na musculatura e a perda de eficiência mecânica compartilham de uma causa fisiológica similar, que pode estar ligada a uma diminuição no $\dot{\mathrm{VO}}_{2 \mathrm{~m}}$. 
Palavras-chave: eficiência metabólica; fadiga muscular; consumo de oxigênio

Fonte Financiadora: $\mathrm{CNPq}$

Efeitos do exercício físico em pacientes com sequelas pós-CVID-19

Campos $\mathrm{MC}^{1 *}$, Nery $\mathrm{T}^{1}$, Starke $\mathrm{AC}^{1}$, Alves $\mathrm{ACB}^{1}$, Aguiar JRAS ${ }^{1}$

${ }^{1}$ Laboratório de Biologia do Exercício Físico (LaBioEx), Universidade Federal de Santa Catarina, Araranguá, Santa Catarina, Brasil

*maria.cristine@ufsc.br

Introdução: A fadiga é a sequela mais prevalente nos pacientes pós-COVID-19 e persiste por meses após a fase aguda. Os pacientes apresentam ainda, dispneia, tosse, mal-estar pós-esforço, distúrbios de atenção, dor musculoesquelética, ansiedade e depressão. Objetivo: avaliar o efeito do exercício sobre as sequelas de pacientes pósCOVID-19. Métodos: estudo piloto, prévio ao estudo clínico RE2SCUE "REabilitação REspiratória em pacientes sobreviventes à COVID-19". Cinco pacientes $(60 \%$ sexo feminino), com média de idade de 53,8 \pm 9,1 receberam oito semanas consecutivas de tratamento, duas vezes na semana. A intensidade do exercício aeróbio foi de 60 a $75 \%$ da frequência cardíaca de reserva, esforço subjetivo entre 4 e 6 pela escala de BORG modificada e a velocidade da esteira em $75 \%$ da média atingida no teste de capacidade de exercício. O fortalecimento em intensidade de $80 \%$ de 10 repetições máximas: 3 séries de 10 repetições com intervalo de 2 minutos. Ao final, era realizado alongamento. A fadiga e dispneia foram avaliadas pelo Pulmonary Functional Status and Dyspnea Questionnaire - Modified version (PFSDQ-M), além disso, o Medical Research Council (MRC) foi aplicado. A ansiedade e depressão avaliadas pelo Hospital Anxiety and Depression Scale (HADS), e a capacidade de exercício avaliada pelo Incremental Shuttle Walk Test (ISTW). A atenção e memória, respectivamente, pelo teste d2-R e The Rey Auditory-Verbal Learning Test (RAVLT). Resultados: Houve redução significativa da fadiga $(p=0,007)$, dispneia $(p=0,007)$ e dos sintomas de ansiedade $(p$ $=0,017)$. Aumento da capacidade de exercício $(p=0,007)$, e melhora da atenção $(p=$ 0,00). Não foi observado melhora nos sintomas depressivos e no desfecho memória. Conclusão: O exercício físico parece ser seguro e pode melhorar as sequelas fadiga, falta de ar, distúrbios de atenção, ansiedade e aumentar a capacidade de exercício dos sobreviventes à COVID-19.

Palavras-chave: Infecções por Coronavírus; Exercício Físico; Reabilitação

Fonte financiadora: CNPq, CAPES, FAPESC e Ministério da Saúde 
Efeitos da quarentena sobre os impactos na alimentação, sono, atividade física, humor e bem-estar de praticantes de Crossfit ${ }^{\circledR}$

Silvestre $\mathrm{JC}^{1,3 *}$, Da Silva $\mathrm{RC}^{2}$, Dos Santos $\mathrm{RVT}^{3}$

${ }^{1}$ Universidade Metropolitana de Santos e Universidade Católica de Santos, Santos, SP, Brasil

${ }^{2}$ Universidade Metropolitana de Santos, Santos, SP, Brasil

${ }^{3}$ Laboratório de Fisiologia e Bioquímica do Exercício, Universidade Federal de São Paulo, São Paulo, SP, Brasil

*j.csilvestre@yahoo.com.br

Introdução: O isolamento social causado pela quarentena impactou no afastamento dos treinos, gerando alterações de sono, humor e bem-estar e consumo alimentar, bem como diminuição na prática de atividade física. Objetivo: Investigar se a quarentena influenciou na qualidade da alimentação, rotina de treinos, sono, humor e bem-estar dos indivíduos. Métodos: Foram aplicados questionários de sono, humor e bem-estar, de atividade física e do consumo alimentar (diário alimentar de três dias não consecutivos) em 18 praticantes de Crossfit ${ }^{\circledR}$, com média de idade de 34,4 anos \pm 10 anos, adultos, sadios, do sexo masculino e feminino, com a média de prática de Crossfit $\AA^{\circledR}$ de 28,2 meses $\pm 16,9$ meses, durante um período de quatro semanas. Resultados: Os resultados mostraram uma alteração na qualidade do sono (leve e moderadamente alterado), que pode trazer como prejuízo o ganho de peso e desencadear o consumo de alimentos de alto teor de gorduras e açúcares em especial carboidratos simples. $\mathrm{Na}$ primeira semana os níveis de tensão, depressão e raiva estavam mais elevados, considerando que os dados das duas primeiras semanas foram coletados em momento de total isolamento social e as duas últimas semanas foram coletados já em período de flexibilização, na chamada fase amarela da pandemia, os níveis foram diminuindo. Os níveis de fadiga, também aumentaram ao longo do estudo, podendo ser comparado aos níveis de atividade física do questionário internacional de atividade física (IPAQ - versão curta), que foram aumentando também. Conclusão: o isolamento social pode ter provocado efeitos indiretos negativos na vida nos praticantes de Crossfit ${ }^{\circledR}$, pois tiveram alterações de sono, de humor e bem-estar e oscilação da atividade física, fatores que podem impactar no consumo alimentar.

Palavras-chave: sono; ciências da nutrição; ciências da nutrição e do esporte

Fonte Financiadora: Sem financiamentos 
Efeito agudo de uma série de exercício físico contínuo de baixa intensidade na expressão do gene PGC1- $\alpha$

Novaes $G^{1,2 *}$, Pires $R A^{1,2}$, Correia $T^{1} L^{1,2}$, Almeida $A^{1,2}$, Coqueiro $\mathrm{RS}^{1,2}$, Machado $\mathrm{M}^{3,4}$, Queiroz RF ${ }^{1,2}$, Pereira $\mathrm{R}^{1,2}$

${ }^{1}$ Núcleo o Pesquisa em Fisiologia Integrativa, Departamento de Ciências Biológicas, Universidade Estadual do Sudoeste da Bahia (UESB), Jequié, BA, Brasil

${ }^{2}$ Grupo de Pesquisa em Fisiologia Neuromuscular, Departamento de Ciências Biológicas, Universidade Estadual do Sudoeste da Bahia (UESB), Jequié, BA, Brasil

${ }^{3}$ Laboratório de Fisiologia e Biocinética, UNIG Campus V, Itaperuna, RJ, Brasil

${ }^{4}$ Laboratório de Estudos do Movimento Humano, Fundação Universitária de Itaperuna, Itaperuna, RJ, Brasil

*gabonmiranda@gmail.com

Introdução: O exercício induz alterações agudas na bioenergética celular, influenciando os eventos de mitogênese, o qual tem como principal regulador o PGC1- $\alpha$ (Proliferador ativado de peroxissoma gamma receptor coativador 1-alfa). Nesse contexto, o presente estudo teve como objetivo analisar o efeito agudo do exercício contínuo de baixa intensidade (ECBI) na expressão do gene que regula a síntese do PGC1- $\alpha$ em músculos esqueléticos de camundongos. Métodos: 25 camundongos Swiss machos foram divididos em 2 grupos: controle ( $\mathrm{GC}=5$ animais) e exercício ( $\mathrm{GE}=20$ animais), os quais foram submetidos a um protocolo de exercício de nado forçado com lastro contendo $2,5 \%$ do peso do próprio animal por 30 minutos. 5 animais do GE foram sacrificados em horários específicos (imediatamente [0h], 6h, 12h e 24h) após a sessão de exercício. Os camundongos do GC foram eutanasiados sem serem submetidos previamente a exercício físico. O músculo gastrocnêmio foi removido para análise posterior da expressão do Ppargc1a envolvidos na biogênese mitocondrial. As comparações foram realizadas com ANOVA one-way. O nível de significância foi fixado em $p<0,05$. Resultados: Observou-se um pico de expressão do gene Ppargc1a 6h após a realização do exercício, seguido de um retorno em direção à medida basal (i.e., medida do grupo controle) $12 \mathrm{~h}$ após o exercício e um pequeno aumento novamente $24 \mathrm{~h}$ após o exercício. Observou-se diferença significativa entre a medida de $6 \mathrm{~h}$ após o exercício e a medida basal e às medidas obtidas 0 e $12 \mathrm{~h}$ após o exercício $(p<0.05)$. A comparação entre a medida de $24 \mathrm{~h}$ com a condição basal apresentou um $p=0,056$. Conclusão: $O$ pico da expressão do gene Ppargc1a ocorre ao redor de 6h após o ECBI, seguido de uma tendência a redução à condição basal e novo aumento $24 \mathrm{~h}$ após o exercício, o que sugere uma dinâmica não-linear da expressão deste gene após o exercício.

Palavras-chave: exercício; biogênese mitocondrial; estresse oxidativo. 
Fonte Financiadora: Fundação de Amparo à Pesquisa do Estado da Bahia (FAPESB) (APP0024/2016 e RED038/2014), Conselho Nacional de Desenvolvimento Científico e Tecnológico (CNPq) (462401/2014-6)

\section{Aptidão cardiorrespiratória e frequência cardíaca de recuperação são preditores de mortalidade em idosos hipertensos?}

Costa $\mathrm{BM}^{1 *}$, Schamne $\mathrm{JC}^{1,2}$, Okuno $\mathrm{NM}^{1}$

${ }^{1}$ Universidade Estadual de Ponta Grossa/Hospital Universitário Regional dos Campos Gerais, Ponta Grossa, Paraná, Brasil

${ }^{2}$ Universidade Federal do Paraná, Curitiba, Paraná, Brasil

*bruno.mtt.tkd@hotmail.com

Introdução: A hipertensão arterial é uma das doenças mais prevalentes em idosos. Nessa população, frequentemente, há menores níveis de aptidão cardiorrespiratória (ACR) e disfunção autonômica pós-exercício, a qual pode ser avaliada pela frequência cardíaca de recuperação (FCR). Todavia, o papel desses indicadores como preditores de mortalidade nesses indivíduos ainda não está esclarecido. O objetivo deste estudo foi avaliar se ACR e FCR são preditores de mortalidade em idosos hipertensos. Métodos: Participaram do estudo 219 idosos hipertensos, que realizaram um teste incremental em esteira ergométrica (protocolo de Bruce) até a exaustão voluntária. A ACR foi estimada a partir do desempenho atingido no teste incremental, sendo divididos em dois grupos: baixa ACR $\left(\mathrm{VO}_{2 m a ́ x}<21 \mathrm{ml} / \mathrm{kg} / \mathrm{min} ; \mathrm{n}=114\right)$, alta $\mathrm{ACR}\left(\mathrm{VO}_{2 \text { máx }} \geq 6 ; \mathrm{n}=105\right)$. A FCR foi analisada 60s após o encerramento do teste, sendo novamente divididos em dois grupos: FCR anormal (FCR < 13 bpm; $n=117$ ), FCR normal (FCR $\geq 13$ bpm; $n=102$ ). Posteriormente, os voluntários foram acompanhados durante um período de até 66 meses. O desfecho principal analisado foi a mortalidade independente de causa. Foi utilizado o estimador de Kaplan-Meier para comparar a proporção de mortalidade entre os grupos, assim como, foi calculado o risco relativo $(R R)$ e intervalo de confiança (IC95\%). Resultados: Não houve diferença entre os grupos FCR anormal e normal ( $p>$ $0,05)$, mesmo tendo apresentado um $R R$ aumentado no grupo $F C R$ anormal $(R R=2,9$; IC95\% = 0,8-10,2). No entanto, na comparação entre baixa ACR e alta ACR houve diferença significativa $(p=0,03)$, com maior incidência de mortalidade no grupo baixa ACR. Além disso, o RR foi bastante elevado ( $R R=5,1$; IC95\% = 1,2-23,1). Conclusão: Em idosos hipertensos, a baixa aptidão cardiorrespiratória parece ser um fator preditivo de mortalidade mais importante do que o indicador autonômico.

Palavras-chave: Disfunção autonômica; Doenças cardiovasculares; Atividade física. 
Fonte Financiadora: CNPq, CAPES Efeitos da restrição do fluxo sanguíneo sobre os biomarcadores de dano oxidativo
em indivíduos saudáveis: revisão sistemática e meta-análise

Ferlito $\mathrm{JV}^{1 *}$, Rolnick $\mathrm{ND}^{2}$, Ferlito $\mathrm{MV}^{1}$, De Marchi $\mathrm{T}^{1,3,4}$, Salvador $\mathrm{M}^{1}$

${ }^{1}$ Laboratório de Estresse Oxidativo e Antioxidantes (LEOA), Programa de PósGraduação em Biotecnologia, Universidade de Caxias do Sul, Caxias do Sul, RS, Brasil ${ }^{2}$ The Human Performance Mechanic, Lehman College, New York, New York, USA

${ }^{3}$ Centro-Universitário Cenecista de Bento Gonçalves, Bento Gonçalves, RS, Brasil

${ }^{4}$ Laboratório de Fototerapia e Tecnologias Inovadoras em Saúde (LaPIT), Programa de Pós-Graduação em Ciências da Reabilitação, Universidade Nove de Julho, São Paulo,SP, Brasil

*joaoferlito@yahoo.com.br

Introdução: Nos últimos anos é crescente o interesse científico por inovações em técnicas de treinamento, dentre as quais se destaca o exercício com restrição do fluxo sanguíneo (RFS). Isso ocorre devido a sua capacidade de induzir a hipertrofia e ganho de força muscular similar ao treinamento de alta intensidade (TAI, 70-80\% de 1RM), porém com baixa intensidade (20-30\% de 1RM). Entretanto, ao nosso conhecimento, não há estudos que descrevam sistematicamente os efeitos do treinamento de força com RFS sobre o dano oxidativo em comparação com o TAl em indivíduos saudáveis. Métodos: Esta revisão sistemática e meta-análise de ensaios clínicos seguiram as diretrizes PRISMA. As bases de dados da PubMed, EMBASE, CINAHL, CENTRAL, PeDro e Biblioteca Virtual em Saúde foram utilizadas para a busca dos artigos. Não houve restrição de ano ou idioma. O risco de viés e a certeza da evidência foram avaliados usando a escala PeDro e o sistema GRADE, respectivamente. O tamanho de efeito foi calculado pela diferença média padronizada (DMP). Resultados: Cinco estudos ( $n=51,22,54 \pm 4,8$ anos) com risco moderado a alto de viés (5 a 6 pontos na escala PeDro) foram incluídos. Nossos achados demonstraram que há baixa certeza de evidência de que RFS gera um menor dano oxidativo a proteínas (DMP $=-0.62$ IC 95\% -1.08 a -0.17) e lipídeos (DMP = -0.86, IC 95\% -1.50 a -0.22) quando comparado ao TAI. Apenas um ensaio avaliou que o dano oxidativo 24 e 48 horas após o exercício, e reportou maior dano oxidativo a lipídios a favor do TAI $(p<0,05)$. Conclusão: O corpo de evidências atual sugere que uma sessão de exercício com RFS produz menor dano oxidativo a lipídeos e proteínas do que o exercício com TAl. Porém, mais estudos são necessários para confirmar estas conclusões.

Palavras-chave: estresse oxidativo; restrição de fluxo sanguíneo; exercício; dano oxidativo 


\section{Efeito da terapia de fotobiomodulação no dano oxidativo induzido pelo exercício: revisão sistemática e meta-análise}

Ferlito $\mathrm{JV}^{1 *}$, Ferlito, $\mathrm{MV}^{1}$, Leal-Junior ECP ${ }^{3}$, De Marchi $\mathrm{T}^{1,2,3}$, Salvador $\mathrm{M}^{1}$

${ }^{1}$ Laboratório de Estresse Oxidativo e Antioxidantes (LEOA), Programa de PósGraduação em Biotecnologia, Universidade de Caxias do Sul, Caxias do Sul, RS, Brasil ${ }^{2}$ Centro-Universitário Cenecista de Bento Gonçalves, Bento Gonçalves, RS, Brasil

${ }^{3}$ Laboratório de Fototerapia e Tecnologias Inovadoras em Saúde (LaPIT), Programa de Pós-Graduação em Ciências da Reabilitação, Universidade Nove de Julho, São Paulo (SP) Brasil

*joaoferlito@yahoo.com.br

Introdução: O estresse oxidativo induzido pelo exercício tem sido um campo de pesquisa em constante crescimento, devido à sua relação com os processos de fadiga, dano muscular e diminuição da capacidade de produção de força muscular. Nesse sentido, a terapia de fotobiomodulação (TFBM) tem demonstrado ser um recurso capaz de melhorar o desempenho, reduzindo a fadiga e os danos musculares. Portanto, realizamos uma revisão sistemática com meta-análise objetivando demonstrar o efeito da TFBM sobre os marcadores de dano oxidativo após exercícios de alta intensidade. Métodos: Esta revisão sistemática e meta-análise de ensaios clínicos seguiram as diretrizes PRISMA. As bases de dados da PubMed, EMBASE, CINAHL, CENTRAL, PeDro e Biblioteca Virtual em Saúde foram utilizadas para a busca dos artigos. Não houve restrição de ano ou idioma; apenas estudos em humanos que compararam a aplicação de TFBM com placebo foram incluídos. O risco de viés e a certeza da evidência foram avaliados usando a escala PEDro e o sistema GRADE, respectivamente. Resultados: Seis estudos ( $n=118,22,14 \pm 4,41$ idade) foram elegíveis para esta revisão, com qualidade metodológica de moderada a excelente. A certeza da evidência encontrada foi de baixa a moderada, ainda assim, nossos achados sugerem que uma sessão de TFBM é capaz de diminuir os danos aos lipídios (DM =-0,65; IC 95\% $-1,11$ a $-0,20 ; 12=94 \% ; p=0,005)$ e proteínas (DM = -0,51; IC 95\% -0,89 a -0,14, I2 = $68 \%, p=0,008)$ induzidos pelo exercício. Observamos que esse efeito permaneceu após até 96 horas após o exercício. Conclusão: Embora haja um número limitado de ensaios disponíveis na literatura sobre este tópico, o corpo de evidências sugere que o TFBM pode diminuir o dano oxidativo induzido pelo exercício por até 96 horas.

Palavras-chave: fotobiomodulação; dano oxidativo; estresse oxidativo; exercício. 
Polimorfismo i/d do gene da enzima conversora de angiotensina (eca) e desempenho físico em tarefas de endurance e de força explosiva

Cardoso $\mathrm{DR}^{1,2}$, Freire $\mathrm{IV}^{1,2}$, Oliveira $\mathrm{AA}^{1,2}$, Machado $\mathrm{M}^{3,4}$, Schettino $\mathrm{L}^{1,2}$, Barbosa $A \mathrm{AL}^{1,2}$, Pereira $R^{1,2}$

${ }^{1}$ Núcleo o Pesquisa em Fisiologia Integrativa, Departamento de Ciências Biológicas, Universidade Estadual do Sudoeste da Bahia (UESB), Jequié, BA, Brasil

${ }^{2}$ Grupo de Pesquisa em Fisiologia Neuromuscular, Departamento de Ciências Biológicas, Universidade Estadual do Sudoeste da Bahia (UESB), Jequié, BA, Brasil ${ }^{3}$ Laboratório de Fisiologia e Biocinética, UNIG Campus V, Itaperuna, RJ, Brasil

${ }^{4}$ Laboratório de Estudos do Movimento Humano, Fundação Universitária de Itaperuna, Itaperuna, RJ, Brasil

Introdução: Os estudos que investigam a associação do polimorfismo I/D da Enzima Conversora da Angiotensina (ECA) e o desempenho físico durante os exercícios têm sido limitados a atletas ou envolvendo apenas um tipo de exercício (força ou resistência). Nossa hipótese é que o alelo $D$ estaria associado à melhor desempenho em tarefas baseadas na força explosiva, enquanto o alelo I, especialmente os indivíduos homozigotos, em tarefas baseadas em condicionamento cardiorrespiratório (CCR). Este estudo teve como objetivo investigar a associação do polimorfismo I/D do gene da ECA e o desempenho em tarefas de força e de CCR. Métodos: 73 homens saudáveis (18-19 anos), que foram genotipados quanto ao genótipo I/D da ECA e classificados como II ( $\mathrm{n}$ $=14)$, ID ( $n=29)$ ou DD ( $n=30)$, e submetidos a duas tarefas: 1) medida da força isométrica máxima de extensão do joelho; 2) teste de corrida de 12 minutos (máxima distância alcançada nesta tarefa). Com base em amostras envolvendo atletas, os indivíduos foram agrupados de 2 formas: 1) genótipo II vs genótipo ID + DD; 2) genótipo II+ID vs genótipo DD. O teste t não pareado comparou o desempenho dos grupos nas tarefas estudadas. O nível de significância foi estabelecido em $p<0,05$. Resultados: Diferenças significativas foram observadas entre os grupos nas duas tarefas $(p<0,05)$. Melhor desempenho na tarefa baseada em CCR foi observado nos grupos que carregam o alelo I (i.e., genótipo II e grupo II+ID), enquanto maior produção de força explosiva foi observada para o genótipo ID+DD quando comparado ao genótipo II. Conclusão: Pessoas que carregam o alelo I, em homozigose II ou heterozigose ID são propensos a melhor desempenho em tarefas de CCR, enquanto os carregam o alelo $D$ (i.e., ID e DD) são propensos a atividades de força explosiva.

Palavras-chave: sistema renina-angiotensina; gene candidato; Polimorfismo ACE I/D; exercício, desempenho físico.

Fonte Financiadora: CNPq, CAPES 
Suplementação de creatina melhora o desempenho físico e sem efeitos negativos nos marcadores hepáticos e de função renal em jovens fisicamente treinados

Malta $\mathrm{FL}^{3,4 *}$, Almeida $\mathrm{D}^{1}$, Pereira $\mathrm{R}^{3,4}$, Borges $\mathrm{EQ}^{1}$, Rocha $\mathrm{LS}^{3}$, Machado $\mathrm{M}^{3,4}$

1Laboratório de Fisiologia e Biocinética, UNIG Campus V, Itaperuna, 28300-000, RJ, Brasil

${ }^{2}$ Laboratório de Estudos do Movimento Humano, Fundação Universitária de Itaperuna, Itaperuna, 28300-000, RJ, Brasil

${ }^{3}$ Núcleo Pesquisa em Fisiologia Integrativa, Departamento de Ciências Biológicas, Universidade Estadual do Sudoeste da Bahia (UESB), Jequié 45210-506, BA, Brasil

${ }^{4}$ Grupo de Pesquisa em Fisiologia Neuromuscular, Departamento de Ciências Biológicas, Universidade Estadual do Sudoeste da Bahia (UESB), Jequié 45210-506, $B A$, Brasil

\section{*filipelirio@outlook.com}

Introdução: A segurança da suplementação de creatina tem sido investigada, porém, a segurança de um esquema de suplementação de alta dose/curto prazo, seguido de baixa dose/longo prazo, associado a um programa de treinamento contra-resistido, ainda não foi estudou. O objetivo deste estudo foi avaliar a segurança de 28 dias de suplementação de creatina monohidratada em um estudo duplo-cego controlado por placebo, avaliando os indicadores de saúde do sangue e da urina em praticantes de treinamento contra-resistido. Métodos: Trinta e quatro homens saudáveis foram aleatoriamente designados para receber suplementação de creatina (CREA / 7 dias, 0,3 $\mathrm{g} / \mathrm{kg}$ de massa corporal +21 dias, $0,03 \mathrm{~g} / \mathrm{kg}$ ) ou grupo placebo (PLA). Os voluntários participaram de uma intervenção de treinamento de resistência ( 6 exercícios, 3 séries de 8-12 repetições por exercício a 85\% de 1RM, 3 dias/semana). Amostras de sangue foram coletadas em jejum, sempre pela manhã, antes, 7 e 28 dias após a suplementação. A atividade plasmática de Aspartato Aminotransferase, Alanina Aminotransferase, fosfatase alcalina e creatinina foram comparadas usando ANOVA two-way com medidas repetidas (2 grupos [CREA e PLA] x 2 medidas ["POS7 menos PRE" e "POS28 menos PRE"]). Resultados: O grupo CREA apresentou aumento significativo de 1RM (PÓS28 menos PRE) em todos os exercícios avaliados, quando comparado ao grupo PLA. Fosfatase alcalina, creatinina se mostraram significativamente maiores nas comparações POS7 e POS28 quando comparados ao PLA, no entanto, nenhum dos grupos apresentou níveis plasmáticos acima do ponto de corte clinicamente recomendado para os marcadores estudados. Conclusão: Nossos dados sugerem que o esquema de suplementação de creatina aqui estudada, concomitantemente ao treinamento de resistência, melhora o desempenho físico sem risco evidente para a saúde de jovens fisicamente treinados com exercício contraresistido. 
Palavras-chave: Suplemento; desempenho físico; musculação; rim; fígado; segurança. Fonte Financiadora: Recursos próprios

\section{Barreiras para a prática de atividade física e sua associação com fatores sociodemográficos em adultos com obesidade}

Rosa $F^{1 *}$, Streb ARS ${ }^{1}$, Bertuol $C^{1}$, Del Duca GF ${ }^{1}$

Grupo de Estudo e Pesquisa em Exercício Físico e Doenças Crônicas Não Transmissíveis (GEP EFID), Universidade Federal de Santa Catarina, Florianópolis, SC, Brasil

*fr.fernanda@hotmail.com

Introdução: A atividade física influencia positivamente no combate à obesidade, porém os indivíduos podem perceber barreiras que os impedem de manter-se ativos. Objetivou-se investigar a prevalência de barreiras à prática de atividade física e fatores sociodemográficos associados em adultos com obesidade. Métodos: Recorte transversal de um ensaio clínico randomizado e controlado realizado com adultos com obesidade, utilizando dados de baseline. Foram coletadas informações sociodemográficas e de barreiras percebidas, através do questionário proposto por Martins e Petroski (2000). Na análise de dados, empregou-se o teste qui-quadrado de Pearson para variáveis categóricas (sexo, trabalho, estado civil, cor da pele) e o teste $t$ para variáveis contínuas (idade, escolaridade), adotando-se $p<0,05$. Resultados: Participaram do estudo 67 indivíduos com 34,6 $( \pm 7,1)$ anos, que estudaram 15,8 $( \pm 2,7)$ anos. $60,9 \%$ eram do sexo feminino, $79,7 \%$ trabalhavam, $36,2 \%$ não tinha companheiro e $81,2 \%$ eram brancos. As principais barreiras percebidas foram jornada de trabalho extensa $(46,3 \%)$, recursos financeiros $(44,8 \%)$, falta de energia (cansaço físico) $(44,8 \%)$, falta de companhia (43,3\%) e falta de equipamento disponível $(29,8 \%)$. Pequena parcela relatou medo de lesionar-se (1,5\%), enquanto a barreira relacionada à dores leves e/ou mal-estar não foi mencionada por nenhum participante. A barreira mais prevalente não teve associação significativa com as variáveis sociodemográficas. Recursos financeiros e falta de energia foram associados com a cor da pele $(p=0,02 ; p=0,01)$, sugerindo que indivíduos brancos percebem mais barreiras, enquanto a falta de companhia associou-se com o sexo feminino $(p=0,008)$ e a falta de equipamento, com indivíduos que trabalham $(p=0,01)$. Conclusão: $A$ jornada de trabalho extensa foi a principal barreira à atividade física apontada por adultos com obesidade, e não foi associada com variáveis sociodemográficas. Dores leves/mal-estar não foram relatadas pelos 
participantes. Variáveis sociodemográficas como sexo, trabalho e cor da pele estiveram associadas à diferentes barreiras à atividade física.

Palavras-chave: doença crônica; estilo de vida; atividade motora; barreiras.

Fonte Financiadora: CAPES

\section{Suplementação e sugestão de suplementação aguda de creatina induzem melhoria de desempenho em supino}

Cunha APS ${ }^{3,4 *}$, Aguiar MS ${ }^{1}$, Pereira $\mathrm{R}^{3,4}$, Machado $\mathrm{M}^{3,4}$

${ }^{1}$ Laboratório de Fisiologia e Biocinética, UNIG Campus V, Itaperuna, RJ, Brasil

${ }^{2}$ Laboratório de Estudos do Movimento Humano, Fundação Universitária de Itaperuna, Itaperuna, RJ, Brasil

${ }^{3}$ Núcleo o Pesquisa em Fisiologia Integrativa, Departamento de Ciências Biológicas, Universidade Estadual do Sudoeste da Bahia (UESB), Jequié, BA, Brasil

${ }^{4}$ Grupo de Pesquisa em Fisiologia Neuromuscular, Departamento de Ciências Biológicas, Universidade Estadual do Sudoeste da Bahia (UESB), Jequié, BA, Brasil

*souzacunhaanapaula@gmail.com

Introdução: Afirmações anedóticas sobre melhora da performance após suplementação aguda de creatina são cada vez mais frequentes, mas inferências a este respeito não são reportados na literatura científica. O objetivo deste estudo foi comparar o desempenho em séries de supino 30 minutos após suplementação de creatina, sugestão de suplementação de creatina (ingerir dextrose sob a alegação de ser creatina), suplementação de dextrose e sem qualquer suplementação. Métodos: Quinze homens saudáveis (18-26 anos) foram submetidos a 4 sessões de supino reto ( 3 séries a 10RM), realizadas até a falha concêntrica. Em cada sessão foi realizada sob uma condição experimental: 1) sem qualquer suplementação [CONTROLE]; 2) suplementação de creatina $(0,3 \mathrm{~g} / \mathrm{kg})$, sendo informados de que recebiam este suplemento [CREA]; 2) dextrose $(0,3 \mathrm{~g} / \mathrm{kg})$, sendo informados de que recebiam este suplemento [DEXT]; 3) dextrose $(0,3 \mathrm{~g} / \mathrm{kg})$, sendo informados de que recebiam creatina [PLA_CREA]. A ordem de realização das condições foi randômica e nas sessões com suplemento, o mesmo foi oferecido 30 minutos antes da sessão. O número de repetições em cada série e o total de repetições na sessão foram comparados usando ANOVA two-way com medidas repetidas. Resultados: O número de repetições reduziu significativamente e de forma linear ao longo das séries $(p<0,05)$. O número médio de repetições foi significativamente maior em todas as condições suplementadas quando comparadas à sessão CONTROLE $(p<0,05)$. Observou-se interação significativa tratamento $x$ séries, com maior número de repetições observado nas condições de suplementação (CREA, PLA_CREA e DEXT) na primeira, segunda e terceira séries, 
quando comparada ao CONTROLE $(p<0,05)$. Conclusão: As condições CREA, PLA_CREA e DEXT, induzem melhora do desempenho em séries de supino igualmente, indicando que o benefício da suplementação aguda de creatina se deve a efeitos psicológicos.

Palavras-chave: suplemento; desempenho físico; musculação; creatina.

Influência da suplementação nutricional com farinha de maca amarela (Lepidium meyenii walp.) na memória e densidade neuronal hipocampal de ratos adolescentes submetidos a exercício físico

Sales VS ${ }^{1 *}$, Sales $\mathrm{EPN}^{2}$, Cabral FR ${ }^{2,3}$, Arida $\mathrm{RM}^{1}$

${ }^{1}$ Universidade Federal de São Paulo, São Paulo, Brasil

${ }^{2}$ Faculdade de Ciências Médicas da Santa Casa de São Paulo, São Paulo, Brasil

${ }^{3}$ Instituto Israelita de Ensino e Pesquisa Albert Einstein, São Paulo, Brasil

*valter.pernambuco@gmail.com

Introdução: A nutrição saudável e o exercício físico estimulam modificações no cérebro em um processo denominado de neuroplasticidade. Este fenômeno acontece com maior intensidade no início do desenvolvimento. Deste modo, o uso da farinha de Lepidium meyenii (maca peruana) em razão das propriedades nutricionais e medicinais já descritas, como neuroproteção e melhora da cognição, motivou-nos a investigar se existe influência da suplementação com farinha de maca associada ou não ao exercício físico, sobre o desempenho da memória e densidade neuronal no hipocampo, em ratos na adolescência. Métodos: Foram utilizados ratos Wistar pesando em média $140 \mathrm{~g}$, com 21 dias de idade, divididos em grupos, controle, exercício, maca e maca + exercício. Durante o período pós-natal (P21 a P60), os animais foram suplementados com uma dose de farinha de maca (2000 mg/kg) e submetidos a corrida na esteira. Após este período, foram realizados os testes do campo aberto, reconhecimento de objetos e esquiva passiva do tipo step down. Ao final destes experimentos, os animais foram perfundidos e o tecido cerebral retirado e analisados por imuno-histoquímica utilizando o anticorpo NeuN e os neurônios quantificados por densidade óptica por meio do Software ImageJ. Resultados: Os animais não apresentaram alteração da locomoção, excluindo uma possível interferência no resultado dos testes. A farinha de maca, o exercício físico e a associação destas intervenções melhoraram o desempenho da memória de curta e longa duração nos testes comportamentais e induziram aumento da densidade neuronal no hipocampo (giro dentado, hilo, CA1 e CA3). Conclusão: A suplementação nutricional com farinha de maca e exercício físico melhoraram o desempenho da memória e aumentaram a densidade neuronal no hipocampo, mas sem 
efeito aditivo quando associadas. Nossos resultados mostram que o exercício físico, as macamidas e ácidos graxos poli-insaturados presentes na Lepidium meyenii promovem efeitos positivos na plasticidade hipocampal.

Palavras-chave: exercício físico; Lepidium; plasticidade neuronal; memória. Fonte Financiadora: $\mathrm{CNPq}$

\section{Quimioterápico doxorrubicina causa sarcopenia em camundongos}

Cella $\mathrm{PS}^{1 *}$, Marinello $\mathrm{PC}^{2}$, Búçu $\mathrm{IP}^{1}$, Nunes $\mathrm{JHC}^{1}$, Chimin $\mathrm{P}^{1}$, Deminice $\mathrm{R}^{1}$

${ }^{1}$ Universidade Estadual de Londrina, Departamento de Educação Física, Londrina, PR, Brasil

${ }^{2}$ Universidade Estadual de Londrina, Departamento de Patologia Geral, Londrina, PR, Brasil

*paolascella@gmail.com

Introdução: O A doxorrubicina (DOX) é um quimioterápico com potente ação antitumoral, muito utilizado no tratamento do câncer. A cardiotoxicidade, caracterizada por perda de massa e função do músculo cardíaco, é o principal efeito colateral deste quimioterápico. De fato, muitos sobreviventes do câncer sofrem com cardiomiopatias induzidas pela DOX. Entretanto, os efeitos dos ciclos de quimioterapia usando DOX sobre o músculo esquelético e sua função são pouco conhecidos. Com isso, o objetivo do trabalho foi determinar o efeito de ciclos de DOX sobre os principais moderadores da sarcopenia: perda de massa e força musculares e disfunções físicas em camundongos. Métodos: Camundongos C57-BL machos foram divididos em dois grupos: Controle $(n=14)$ e tratados com DOX $(\mathrm{n}=14)$. A DOX (6 mg/kg i.p.- total de $24 \mathrm{mg} / \mathrm{kg})$ foi administrada a cada quatro dias por um total de 15 dias. O grupo controle recebeu o mesmo volume de água destilada, nas mesmas condições. Os testes de Grip Strength Meter e de 1RM em escada foram utilizados para análise de força muscular. A atrofia muscular foi avaliada pela área de secção transversa do músculo gastrocnêmico. O diâmetro dos cardiomiócitos foi analisado como parâmetro de cardiotoxicidade. Resultados: 0 tratamento com a DOX promoveu cardiotoxicidade demonstrada pela atrofia do coração (19\%). O tratamento com DOX promoveu ainda mudança nos principais componentes da sarcopenia, como redução da força $20 \%(p<0,05)$ determinada usando os testes de Grip Strenght e de 1RM; além de atrofia do músculo gastrocnêmio (10\%). Conclusão: Duas semanas de tratamento com DOX promoveu perda de força e atrofia em camundongos, principais definidores da sarcopenia.

Palavras-chave: função muscular; perda de força; quimioterapia 
Fonte financiadora: CAPES

\title{
O efeito de concussões recorrentes associadas a prática de exercício físico de natação na comunicação entre cérebro e intestino de ratos
}

\author{
Godinho DB1 Lima GC ${ }^{1 *}$, Cipolat RP ${ }^{1}$, Machado FG ${ }^{1}$, Nascimento AS ${ }^{1}$, Royes LFF \\ ${ }^{1}$ Universidade Federal de Santa Maria, Santa Maria, RS, Brasil \\ *gabrielcorrealima2@gmail.com
}

Introdução: A concussão, uma alteração na função cerebral ocasionada por uma força externa, chama atenção por seus efeitos sutis, principalmente em órgãos periféricos, que podem ser somados e agravar o dano inicial da lesão. O intestino, um órgão linfoide secundário que compõe o trato digestório e que apresenta um vasto microbioma, é envolvido no funcionamento de processos complexos como a homeostase eletrolítica ao longo do trato intestinal e os movimentos peristálticos de contração e relaxamento do musculo liso, regulados primariamente pelo Sistema Nervoso Entérico (SNE). Modulações no intestino de animais submetidos à traumatismos sugerem atuação do eixo bidirecional cérebro-intestino durante estados patológicos. Métodos: Nosso trabalho investigou os efeitos de 10 concussões associadas à prática de exercício físico no intestino e nas suas vias de comunicação com o cérebro de ratos jovens. Ratos Wistar, machos, foram randomizados, submetidos à um protocolo de natação de cinco semanas, onde duas vezes a cada semana sofreram concussão pelo modelo de queda livre de peso, imediatamente após o exercício. Resultados: Análises sete dias após a última sessão de natação mostraram que concussões recorrentes e intervaladas são capazes de afetar o funcionamento normal do cólon proximal destes animais. Nosso modelo de concussões causou aumento na lipoperoxidação e parâmetros colinérgicos, embora não modulou per se a atividade da enzima $\mathrm{Na}+, \mathrm{K}_{+}-$ATPase. O exercício físico evitou o aumento dos níveis de malonaldeído, nAChR $\alpha 7$, além de reverter o aumento da atividade da enzima acetilcolinesterase. Além disso, animais treinados que sofreram concussão mostraram um aumento na atividade da enzima $\mathrm{Na}+\mathrm{K}_{+}$- ATPase em relação aos sedentários que sofreram concussões. Conclusão: Compreender como concussões recorrentes afetam também órgãos periféricos pode ser uma nova alternativa para o desenvolvimento de tratamentos ao dano secundário e possíveis neuropatologias induzidas por traumas repetitivos 
Palavras-chave: concussão; eixo cérebro-intestino; nAChR $\alpha 7 ; \mathrm{Na}+\mathrm{K}+\mathrm{ATP}$-ase; Esportes.

Fonte financiadora: CNPq, CAPES, FAPERGS

\section{Efeitos do exercício físico na regulação neuroinflamatória e tumorogênese em animais expostos a um modelo experimental de glioblastoma}

Gattiboni BB ${ }^{*}$, Costa $\mathrm{AK}^{1}$, Marqueze LFB ${ }^{1}$, Vasconcellos FTF${ }^{1}$, Cunha EBD ${ }^{1}$, Pedroso GS$^{2}$, Baldissera AB4, Fernandes LC ${ }^{3}$, Pinho RA ${ }^{1}$

'Laboratório de Bioquímica do Exercício em Saúde, Pontifícia Universidade Católica do Paraná, Curitiba, PR, Brasil

'Laboratório de Fisiologia e Bioquímica do Exercício, Universidade do Extremo Sul Catarinense, Criciúma, SC, Brasil

${ }^{3}$ Laboratório de Metabolismo Celular, Universidade Federal do Paraná, Curitiba, PR, Brasil.

4Laboratório de Matriz Extracelular e Biotecnologia de Venenos, Universidade Federal do Paraná, Curitiba, PR, Brasil

*brunabertogattiboni@gmail.com

Introdução: Gliomas são tumores cerebrais malignos com alta incidência e baixa sobrevida. Alterações da biologia redox tem sido reportada em prévios estudos com protocolos de exercício experimentais e os resultados ainda são inconclusivos. Este estudo avaliou os efeitos de um programa prévio de treinamento físico sobre indicadores de estresse clínicos, comportamentais, tumorigênicos e neuroinflamatórios em animais expostos a um modelo experimental de glioblastoma (GBM). Métodos: 48 camundongos C57BL/6J, randomizados em 4 grupos: Sham, GBM não treinado, Sham treinado e GBM treinado. Foram submetidos a intervenção de treinamento em esteiras por 4 semanas, 6 sessões semanais e intensidade progressiva de 13 a $17 \mathrm{~m} / \mathrm{min}$. Seguida, pela indução do GBM, intracerebroventricular da linhagem tumoral GL261. Foram avaliados os indicadores clínicos, comportamentais, consumo de hídrico e ingesta alimentar. Após 21 dias da cirurgia, foram realizadas a eutanásia e posteriores análises. Resultados: Demonstraram ganhos de massa corporal e maior ingesta alimentar ao final do período experimental nos grupos treinados, adicionalmente, apresentaram alterações pronunciadas no comportamento exploratório. Os animais GBM não treinados apresentaram alterações anatomopatológicas com alta intensidade na imunoexpressão da proteína glial fibrilar ácida (GFAP) e baixa intensidade do receptor do fator de crescimento epidérmico (EGFR), em todos os tecidos. A imunoexpressão do fator de necrose tumoral alfa (TNF- $\alpha$ ) foi moderada na região tumoral nos grupos GBM não treinados e treinados. Enquanto, a intensidade do fator nuclear kappa b (NF-kb), 
interleucina 6 (IL-6) e interleucina 1 beta (IL-1b) se apresentaram fracas nos diferentes grupos e tecidos analisados. Conclusão: Estes achados sugerem que a realização de exercícios físico previamente a indução de GBM exerce potencial efeito neuroprotetor por contribuir para a regulação anatomopatológica e neuroinflamatória. Entretanto, face à algumas limitações do presente estudo, são necessárias investigações adicionais em estudos futuros.

Palavras-chave: exercício; câncer; glioblastoma; estresse oxidativo; inflamação.

Fonte financiadora: CNPq, CAPES

\author{
Determinação da fatigabilidade para teste de frequência de socos no caratê \\ Urbinati $\mathrm{KS}^{1 *}$, Machado $\mathrm{RO}^{1}$, Scheeren $\mathrm{E}^{1}$, Nohama $\mathrm{P}^{1}$ \\ ${ }^{1}$ Programa de Pós-graduação em Tecnologia em Saúde, PUCPR, Curitiba, Brasil \\ *keith.msato@gmail.com
}

Introdução: Protocolos avaliativos para modalidades esportivas auxiliam o cotidiano de técnicos e atletas, especialmente com análises para a compreensão das respostas fisiológicas em situação de fatigabilidade. Objetivo: Comparar as respostas bioquímicas oriundas da fadiga em atletas de caratê. Métodos: Foram avaliados 20 atletas de caratê, praticantes por 12,8 \pm 4,5 anos, faixas marrom e preta, do sexo masculino, nível nacional. Foram aplicados 2 protocolos de forma randomizada cross over com diferença de $24 \mathrm{~h}$. O grupo $1(\mathrm{G} 1, \mathrm{n}=10)$ realizou o teste de frequência de socos na seguinte ordem: (Sem Fadiga - SF) realização de $10 \mathrm{~s}$ de soco contralateral, com $10 \mathrm{~s}$ de intervalo passivo; (Com Fadiga - CF) realização de $10 \mathrm{~s}$ de soco contralateral, com realização de $30 \mathrm{~s}$ de countermovement jump. O grupo 2 (G2, $n=10$ ) realizou o protocolo em ordem inversa. Foram coletadas amostras sanguíneas 'pré', 'pós' e '10 min pós' teste para lactato, glicose, creatinoquinase total (CK), testosterona e cortisol. Realizou-se teste MANOVA $(p<0,05)$, post hoc de Bonferroni para identificar diferenças entre protocolos em diferentes momentos. Resultados: Identificou-se diferenças entre os protocolos SF e CF para as variáveis: lactato 'pós' teste $(F 1,23=0,56 ; p=0,02)$ e '10 min pós' teste ( $F 2$, $21=0,74 ; p=0,001)$; CK 'pós' teste $(F 1,21=0,61 ; p=0,003)$ e '10 min pós' ( $F 1,25=$ $0,45 ; p=0,04)$; e cortisol '10 min pós' ( $F 3,28=0,89 ; p=0,03)$ apresentaram valores elevados para CF; relação testosterona: cortisol '10 min pós' ( $F 2,12=0,71 ; p=0,007)$ com menor valor para CF. Conclusão: Elevados valores de lactato, CK e cortisol para o protocolo CF, especialmente nos momentos 'pós' e '10 min pós' de teste são indicativos 
que o protocolo CF exige elevada intensidade de esforço, garantindo a fatigabilidade do teste.

Palavras-chave: fadiga; arte marcial; fenômeno fisiológico sanguíneo.

Fonte financiadora: Fundação Araucária

\section{Suplementação de ubiquinol não promove regulação redox após overuse muscular}

Falcão $\mathrm{FTV}^{1 *}$, Macedo AC1, Marqueze LB ${ }^{1}$, Costa $\mathrm{AK}^{1}$, Cunha EBB ${ }^{1}$, Fernandes $\mathrm{LC}^{2}$, Pinho RA ${ }^{1}$

${ }^{1}$ Laboratório de Bioquímica do Exercício em Saúde, Pontifícia Universidade Católica do Paraná, Curitiba, PR, Brasil

${ }^{2}$ Laboratório de Metabolismo Celular, Universidade Federal do Paraná, Curitiba, PR, Brasil

*francianevasconcellos@hotmail.com

Introdução: O uso excessivo da musculatura pode promover danos celulares, principalmente quando não há períodos de recuperação suficientes. Conhecido como overuse, essa forma de lesão envolve eventos celulares que elevam a produção de espécies reativas de oxigênio e consequente estresse oxidativo. A suplementação de antioxidantes tem sido utilizada visando restabelecer o estado redox da musculatura, porém, o efeito é limitado devido à dificuldade de atravessar as barreiras membranosas das células. Assim, o objetivo deste trabalho foi avaliar os efeitos do ubiquinol (CoQH2) sobre parâmetros de estresse oxidativo muscular, após exposição a um modelo overuse. Métodos: Ratos Wistar, machos foram randomizados em dois grupos: não exercitados e overuse e subdivididos em controle, suplementados com veículo e CoQH2. Após período de adaptação e teste para estimar a velocidade máxima de esforço, o grupo overuse foi exercitado em esteira, 21 dias contínuos, variando as intensidades: baixa, moderada e alta. CoQH2 foi administrado diariamente, via oral. Após 24 horas da última sessão, os animais foram eutanasiados e extensor longo dos dedos (EDL) e quadríceps foram removidos e processados para análises de força muscular, histopatológicas e parâmetros de estresse oxidativo. Resultados: Os resultados apontam para uma redução do consumo de ração pelos suplementados enquanto a massa corporal e o consumo de água não sofreram alterações significativas. A força muscular máxima e a velocidade de relaxamento muscular tiveram aumento significativo nos animais expostos ao overuse. Uma lesão músculo-tendínea com infiltrado linfo-plasmocitório e hiperplasia de células sinoviais foram observadas nos animais em overuse. Animais overuse, suplementados ou não com ubiquinol, apresentaram níveis de oxidação de 
DCFH aumentados no quadríceps. Não foram observadas alterações no conteúdo de glutationa e da sulfidrila no EDL. Conclusão: Tomados em conjunto, os dados revelam que a suplementação com ubiquinol não exerce efeitos antioxidantes significativos no soro e músculo de animais expostos ao overuse.

Palavras-chave: Exercício físico; overuse; ubiquinona; estresse oxidativo; antioxidante; músculo.

Fonte Financiadora: CNPq, CAPES

\section{II - Resumos de projetos de mestrado ou doutorado}

Regulação dos parâmetros oxidativos, comportamentais e carcinogênicos mediados pelo exercício físico em animais com glioblastoma experimental

Marqueze $\mathrm{LF}^{\star 1}$, Aguiar $\mathrm{A}^{1}$, Alves, $\mathrm{AC}^{1}$, Gattiboni $\mathrm{B}^{1}$, Pedroso $\mathrm{GS}^{2}$, Falcão $\mathrm{F}^{1}$, Nery $\mathrm{T}^{1}$, Pinho RA ${ }^{1}$

${ }^{1}$ Laboratório de Bioquímica do Exercício em Saúde, Pontifícia Universidade Católica do Paraná, Curitiba, PR, Brasil

${ }^{2}$ Laboratório de Biologia do Exercício, Universidade Federal de Santa Catarina, Araranguá, SC, Brasil

*luis_marqueze@hotmail.com

Introdução: Glioblastomas (GBM) são tumores malignos cerebrais de complexa abordagem terapêutica devido a elevada capacidade de infiltração, o que inviabiliza, geralmente, sua ressecção elevando o número de recidivas e consequente morte precoce. Frequentemente, ocorrem em indivíduos adultos com idade entre 50 e 70 anos, com a mediana de sobrevida, pós-diagnóstico, de 12 a 15 meses. As reações de oxirredução são regulares nas atividades biológicas e o seu desabalando positivo (estresse oxidativo) é evidenciado em diversas fisiopatologias, sendo um dos componentes quantitativos de maior relevância sobre a progressão da doença. Desta forma, estudar terapias que possam contribuir para minimizar os efeitos deletérios da doença torna-se extremamente relevante a saúde pública. O exercício físico é proposto como componente auxiliar ao tratamento de diversos cânceres, devido a sua capacidade de influenciar positivamente em diversos mecanismos moleculares e bioquímicos. O estresse oxidativo é um fenômeno celular que está intimamente relacionado ao desenvolvimento e progressão de tumores e é modulado também pelo exercício físico. Métodos: Camundongos C57-black/6I, machos, com 60 dias serão, após a indução do GBM por um modelo de aloenxerto com células de glioma GL261, submetidos a um programa de treinamento progressivo de 3 sessões seguidas de um 
dia de descanso, durante 4 semanas; a velocidade da esteira será progressiva de $50 \%$ a $60 \%$ de intensidade, estabelecida por um teste de esforço anterior, e o tempo de cada sessão será de até $50 \mathrm{~min} /$ dia sem inclinação. Não será utilizado nenhum estímulo nocivo para incentivar a corrida nos animais. Os grupos não-treinados serão mantidos na caixa durante todo período experimental. Após a eutanásia, os córtex pré-frontal, lobos parietais e quadríceps direito serão retirados para análises anatomopatológicas, parâmetros carcinogênicas, inflamatórias e de estresse oxidativo. Resultados esperados: Espera-se que os resultados obtidos possam contribuir para compreensão dos mecanismos de neuroproteção induzidos pelo exercício no GBM.

Palavras-chave: exercício físico, câncer, glioblastoma, estresse oxidativo.

Fonte Financiadora: CNPq, CAPES

\section{Resumo gráfico}

REGULATION OF OXIDATIVE, INFLAMMATORY AND CARCINOGENIC PARAMETERS MEDIATED BY PHYSICAL EXERCISE IN ANIMALS WITH EXPERIMENTAL GLIOBLASTOMA
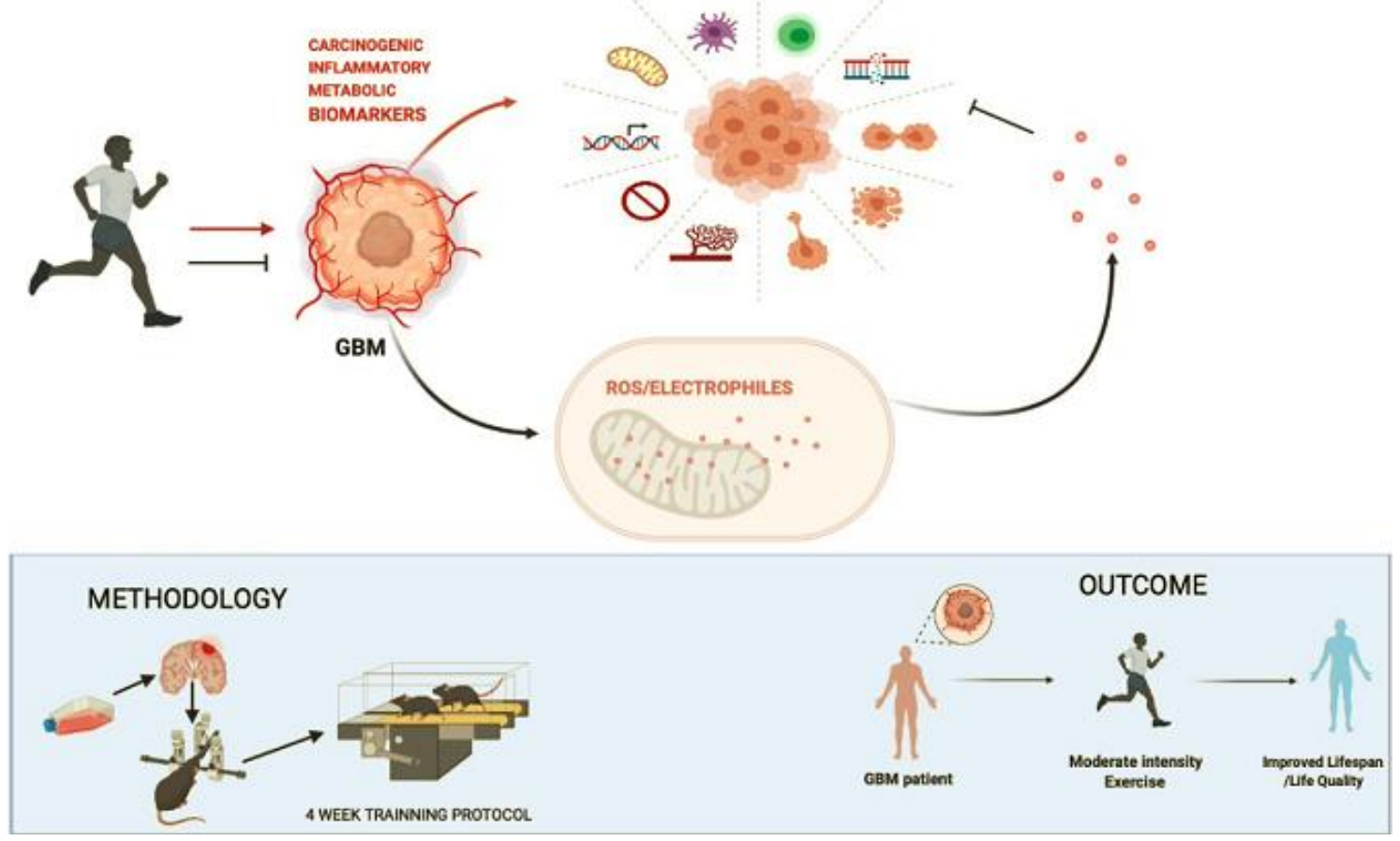
Efeito do consumo agudo do suco de juçara (Euterpe edulis Martius) sobre biomarcadores de estresse oxidativo e fadiga em uma sessão de exercício intervalado de alta intensidade: um ensaio clínico randomizado e cross-over

Copetti CLK ${ }^{1 *}$, Orssatto LBR ${ }^{2}$, Diefenthaeler $\mathrm{F}^{2}$, Silveira TT ${ }^{1}$, Da Silva EL ${ }^{1,3}$, Baptista SL ${ }^{1}$, Mendes $\mathrm{BC}^{1}$, Venske DKR ${ }^{1}$, Vieira FGK ${ }^{1}$, Hinnig $\mathrm{PF}^{1}$, Schulz $\mathrm{M}^{4}$, Fett $\mathrm{R}^{4}$, Di Pietro $\mathrm{PF}^{1}$

${ }^{1}$ Programa de Pós-Graduação em Nutrição, Universidade Federal de Santa Catarina, Florianópolis, SC, Brasil

${ }^{2}$ Laboratório de Biomecânica, Departamento de Educação Física, Universidade Federal de Santa Catarina, Florianópolis, SC, Brasil

${ }^{3}$ Laboratório de Lipídeos, Antioxidantes e Aterosclerose, Departamento de Análises Clínicas, Universidade Federal de Santa Catarina, Florianópolis, SC, Brasil

${ }^{4}$ Departamento de Ciência e Tecnologia de Alimentos, Universidade Federal de Santa Catarina, Florianópolis, SC, Brasil

*candice.lk@hotmail.com

Introdução: O consumo de alimentos ricos em antocianinas, como o fruto juçara (Euterpe edulis Martius), pode oferecer proteção antioxidante durante o exercício, independentemente da duração da intervenção. O objetivo deste estudo foi avaliar o efeito do consumo agudo do suco de juçara sobre biomarcadores do estresse oxidativo e fadiga em uma sessão de exercício intervalado de alta intensidade. Métodos: Em um estudo randomizado, cross-over e controlado, 15 homens fisicamente ativos foram designados para consumir $250 \mathrm{~mL}$ de suco de juçara ou água (controle) $1 \mathrm{~h}$ antes do exercício. Amostras sanguíneas foram obtidas $1 \mathrm{~h}$ antes do exercício, imediatamente após e 1 h após o exercício. Os parâmetros avaliados foram: fenóis totais, ácido úrico, glutationa reduzida (GSH), glutationa oxidada (GSSG), razão GSH:GSSG, capacidade antioxidante total (TAC), estado oxidante total (TOS), índice de estresse oxidativo (IEO), proteínas carboniladas (PC) e as enzimas antioxidantes: glutationa peroxidase (GPx), superóxido dismutase (SOD) e catalase (CAT). Resultados: A partir das mudanças relativas médias foi possível observar uma diminuição do IEO imediatamente após o exercício $(p=0,020)$ e um aumento de GSH 1h após o exercício $(p=0,040)$ após o consumo do suco de juçara comparado ao controle. Também foi observado um aumento nos níveis de fenóis totais $(p=0,020)$ e ácido úrico $(p<0,001)$ ao longo do tempo. Além disso, foi observada redução da fadiga $(p<0,001)$ no grupo que consumiu o suco de juçara. Conclusão: Os resultados indicam que o suco de juçara pode contribuir para as respostas antioxidantes e redução da fadiga após uma sessão de exercício intervalado de alta intensidade.

Palavras-chave: antocianinas; antioxidantes; espécies reativas de oxigênio; estresse oxidativo; treinamento intervalado de alta intensidade; fadiga.

Fonte financiadora: CNPq, CAPES e Programa de Pós-Graduação em Nutrição da Universidade Federal de Santa Catarina 


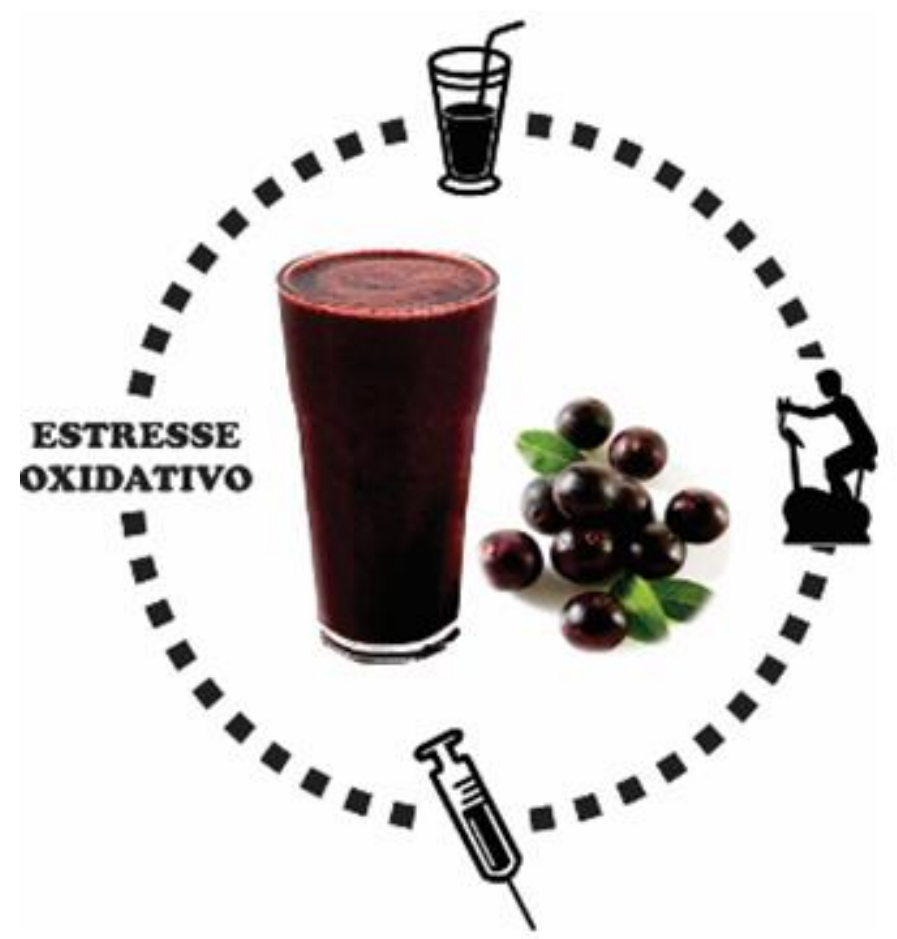

As proteínas que facilitam a entrada célular do SARS-COV-2, ECA2 e PRSTMS2 estão elevadas em tecidos pulmonares de ratos alimentados com uma dieta obesogênica, mas não em ratos alimentados com uma dieta cetogênica

Da Eira $D^{1 *}$, Jani $S^{1}$, Ceddia RB ${ }^{1}$

${ }^{1}$ Muscle Health Research Centre, York University, Toronto, Canadá

*ddaeira@yorku.ca

O objetivo desse estudo foi identificar mecanismos moleculares relacionados a predisposição de indivíduos obesos a desenvolverem sintomas graves após infecção com o novo coronavírus, e investigar se a dieta cetogênica (DC) pode atenuar o risco de doença severa relacionada a SARS-CoV-2. Para isso, ratos da linhagem SpragueDawley foram alimentados com uma das seguintes dietas: dieta padrão (DP), dieta rica em gordura e enriquecida com sacarose (GS), e DC. Após um período de alimentação de 16 semanas, os pulmões dos animais foram extraídos para análise do conteúdo das seguintes proteínas essenciais à entrada celular do SARS-CoV-2: enzima conversora 
de angiotensina 2 (ECA2) e a protease transmembrana serina 2 (PRSTMS2). Também foram medidos outros componentes do sistema renina-angiotensina (SRA) e a expressão gênica de marcadores inflamatórios. Nós observamos que os conteúdos da ECA2 e da PRSTMS2 aumentaram 3,8 e 5,1 vezes, respectivamente, nos pulmões dos ratos alimentados com a dieta GS. Interessantemente, os conteúdos destas proteínas não mudaram nos pulmões dos ratos alimentados com a DC. No entanto, a DC diminuiu o conteúdo da enzima conversora de angiotensina 1 (ECA1). Além disso, a DC reduziu as expressões gênicas do receptor da interleucina-6 (IL6R) e do receptor toll-like 4 (TLR4) em 79\% e 74\%, respectivamente, em relação à dieta GS. Em conjunto, estes dados sugerem que o elevado risco de doença severa em indivíduos obesos infectados com o COVID-19 pode ser atribuído ao aumento das proteínas ECA2 e PRSTMS2 nos pulmões desses pacientes. Esses dados também sugerem que, em indivíduos obesos, a DC pode atenuar a entrada celular do SARS-CoV-2, uma vez que não eleva os conteúdos de ECA2 e PRSTMS2, além exercer um efeito anti-inflamatório em tecidos pulmonares. Isto pode reduzir a migração do vírus para outros tecidos, incluindo o coração e a vasculatura, onde mais danos poderiam ocorrer.

Palavras-chave: dieta cetogênica, SARS-CoV-2; enzima conversora de angiotensina 2

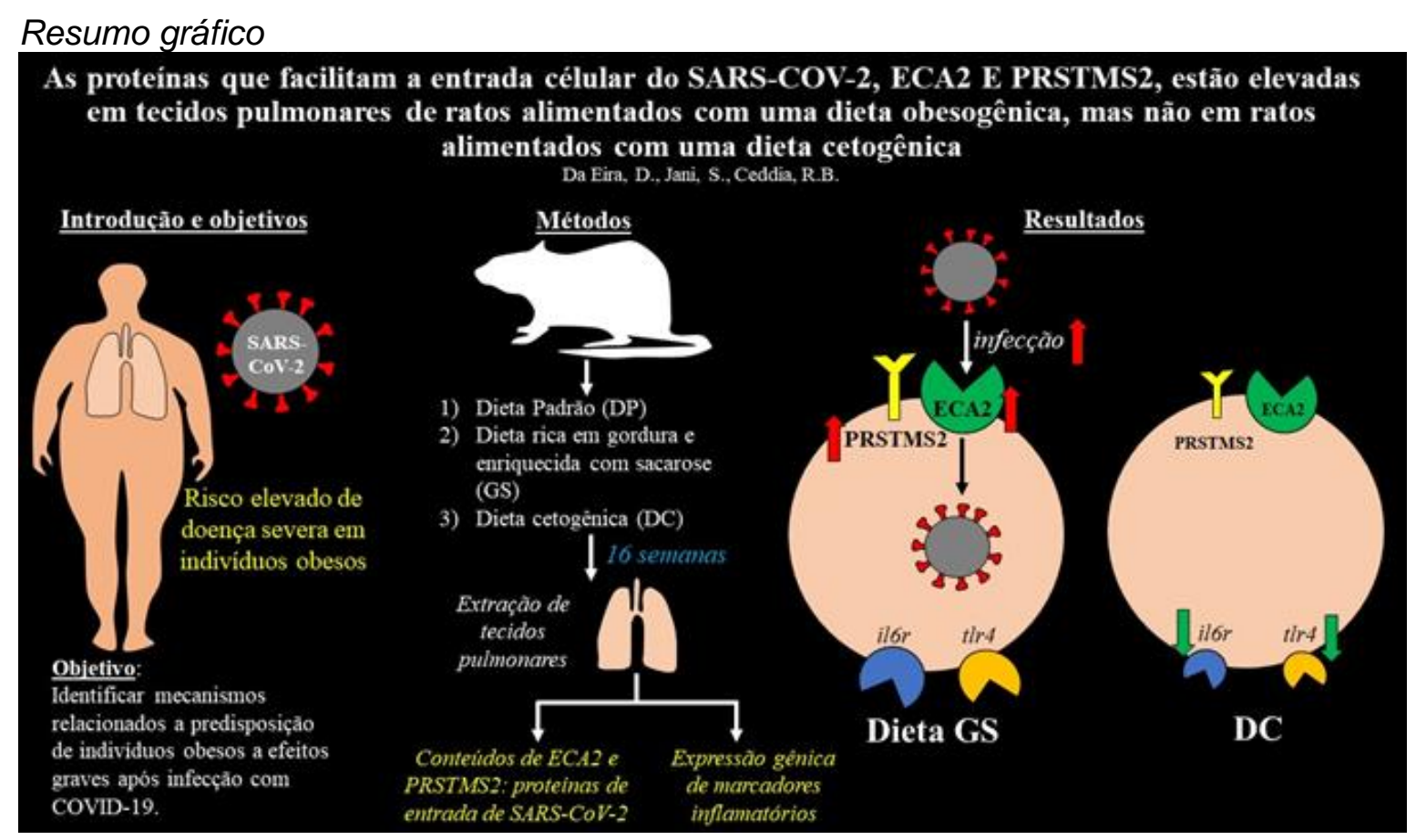


Efeitos da reabilitação cardiopulmonar sobre o comprometimento muscular e disfunção respiratória de médio a longo prazo após infecção por SARS-CoV-2

Terçariol SG ${ }^{1 *}$, Nesi $\mathrm{RT}^{2}$, Dias $\mathrm{CN}^{3}$, Pinho RA ${ }^{1}$

${ }^{1}$ Laboratório de Bioquímica do Exercício em Saúde, Pontifícia Universidade Católica do Paraná, Curitiba, PR, Brasil

${ }^{2}$ Fisioterapeuta, Clínica Nesi Cardiopulmonar, Criciúma, PR, Brasil

${ }^{3}$ Fisioterapeuta, Clínica Reabilit, Brasília, DF, Brasil

${ }^{4}$ Pontifícia Universidade Católica do Paraná Escola de Medicina-PUCPR, Programa de pós-graduação em Ciências da Saúde, Laboratório de Bioquímica do Exercício em Saúde (BIOEX), Curitiba, PR, Brasil

*simone.galbiati@uol.com.br

Introdução: Neste século, os seres humanos passaram por vários surtos epidêmicos, mas nenhum tão devastador como esse coronavírus. O Sars-CoV-2 é uma síndrome respiratória aguda grave 2, também denominado como COVID-19 (do inglês Coronavirus Disease 2019). Sabe-se que o COVID-19 vem causando sequelas respiratórias, diminuição de massa e força muscular esquelética com prejuízo funcional. A reabilitação cardiopulmonar e muscular tem uma importância significativa, principalmente neste momento de pandemia. Mas, os resultados dos estudos ainda são inconsistentes ou, por vezes, contraditórios, e ainda pouco se sabe sobre o futuro das consequências causadas pela doença. Objetivo: Investigar os efeitos da reabilitação cardiopulmonar sobre o comprometimento muscular e disfunção respiratória de médio a longo prazo em pacientes infectados pelo Sars-Cov-2. Métodos: Pacientes que estão realizando ou já realizaram a reabilitação cardiopulmonar pós-COVID, terão seus dados coletados a partir dos seus prontuários de avaliação. Inicialmente, serão coletados: (1) sexo, idade; (2) frequência cardíaca, pressão arterial; (3) avaliação de capacidade funcional (CF), incluindo; Teste de Caminhada de 6 minutos (TC6), Teste do Degrau e Teste de Força Muscular; (4) espirometria, analisando o volume total (VT), capacidade vital (CV) e função pulmonar. As medidas avaliadas serão: Frequência Respiratória (FR), Volume Residual (VR), Volume de Reserva Expiratório (VRE), avaliação de força muscular inspiratória. Esses valores irão analisar o comprometimento muscular e disfunção respiratória desses pacientes. Todas as medidas serão confrontadas com valores de referências conforme os autores sugerem. Resultados esperados: Esperase que os resultados obtidos nessa proposta possam contribuir substancialmente para o avanço do conhecimento na área da reabilitação na pandemia de COVID-19, pois além de investigar os efeitos da reabilitação sobre o comprometimento muscular e respiratório, a presente proposta também relaciona possíveis alterações a médio e longo prazo que venham a ser encontradas nos pacientes infectados pelo Sars-Cov-2.

Palavras-chave: comprometimento muscular; coronavírus; reabilitação cardiopulmonar. 
Resumo gráfico

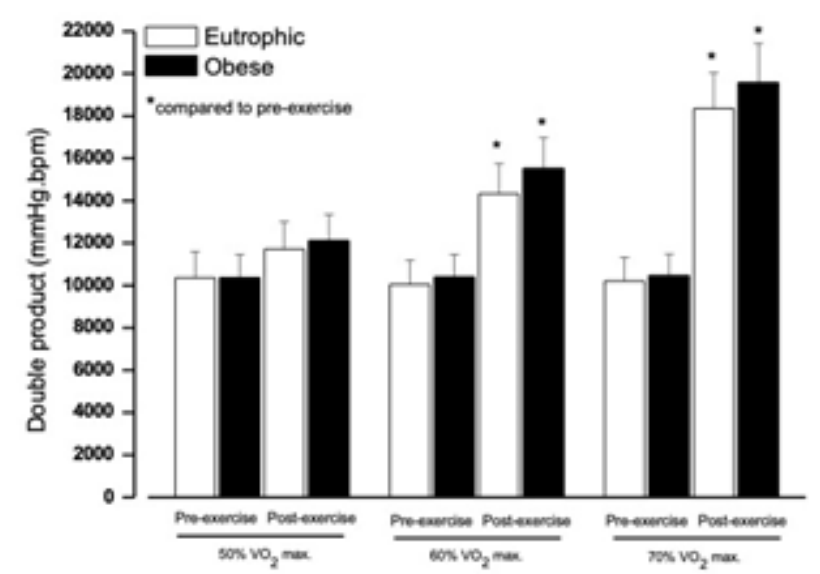

Papel do toll like receptor 4 na resposta lipolítica mediada pelo exercício exaustivo agudo

Cabral-Santos $\mathrm{C}^{1 *}$, Sanches $\mathrm{LS}^{2}$, De Souza Teixeira AA², Rosa-Neto $\mathrm{JC}^{2}$, Lira FS ${ }^{1}$

${ }^{1}$ Laboratório de Fisiologia Celular do Exercício, Departamento de Educação Física, Universidade Estadual Paulista (UNESP) Campus Presidente Prudente, SP, Brasil

${ }^{2}$ Laboratório de Imunometabolismo, Departamento de Biologia Celular e do Desenvolvimento, Universidade de São Paulo (ICB1 - USP), SP, Brasil

*carolina-cabralsantos@hotmail.com

Introdução: A elevação das concentrações de ácidos graxos livres (AGL) durante o exercício é mediada principalmente pela resposta neuroendócrina e, concomitante a esta condição, foi postulado que a endotoxemia por lipopolissacarídeos (LPS) favorece a ativação da resposta inflamatória via Toll Like Receptor 4 (TLR-4) em diferentes tipos celulares. Especula-se que a ativação de TLR-4 favoreceria o processo de lipólise no tecido adiposo (via transcrição de citocinas pró-inflamatórias), aumentando assim a disponibilidade de AGL como substrato circulante. Métodos: Camundongos foram utilizadas duas linhagens de animais: Wild Type C57BL/6J (WT) +Salina e animais TLR4 nocaute (TLR-4-/-), divididos em grupo 1-controle (Rest); 2-exercitado com eutanásia imediatamente pós-exercício (0h); 3-2h pós-exercício (2h) e; 4-6h pós-exercício (6h) (n = 8 por grupo). Além disso, foi adicionado mais um grupo WT que recebeu $10 \mathrm{mg} / \mathrm{kg}$ peso de bloqueador beta-adrenérgico (Propranolol). A sessão de exercício exaustivo agudo consistiu de 50 minutos de corrida em esteira rolante à $60 \%$ da Velocidade Máxima seguida de incremento de $1 \mathrm{~m} / \mathrm{min}$ até a fadiga voluntária. As diferenças entre os grupos e os tempos referente ao perfil metabólico e inflamatório foram analisadas 
pelo teste ANOVA de duas vias e quando necessário o post-hoc de Bonferroni. Resultados: O grupo TLR-4 KO apresentou elevada concentrações de AGL plasmáticos $(p=0,029)$, bem como um decaimento contínuo do conteúdo de triacilglicerol $(p=0,04)$ e glicogênio hepático musculares até 6 h após o exercício $(p=0,001)$ quando comparado com os demais grupos. Além disso, o efeito anti-inflamatório do exercício estimulado pela liberação de IL-10 avaliado nos depósitos retroperitoneal e mesentérico do tecido adiposo estavam prejudicados $(p=0,02)$ quando comparado aos demais grupos. Conclusão: Tomados em conjunto, os resultados sugerem que o TLR-4 tem um importante papel como modulador do metabolismo energético, bem como tem participação na produção aguda de citocinas anti-inflamatórias após o exercício exaustivo.

Palavras-chave: exercício; metabolismo; inflamação; fatores transcricionais; toll-like receptor 4.

Fonte financiadora: Fundação de Amparo à Pesquisa do Estado de São Paulo Processo FAPESP n. 2015/26148-0

Resumo gráfico

\section{Papel do Toll Like Receptor 4 (TLR-4) na resposta lipolítica mediada pelo exercício exaustivo agudo}
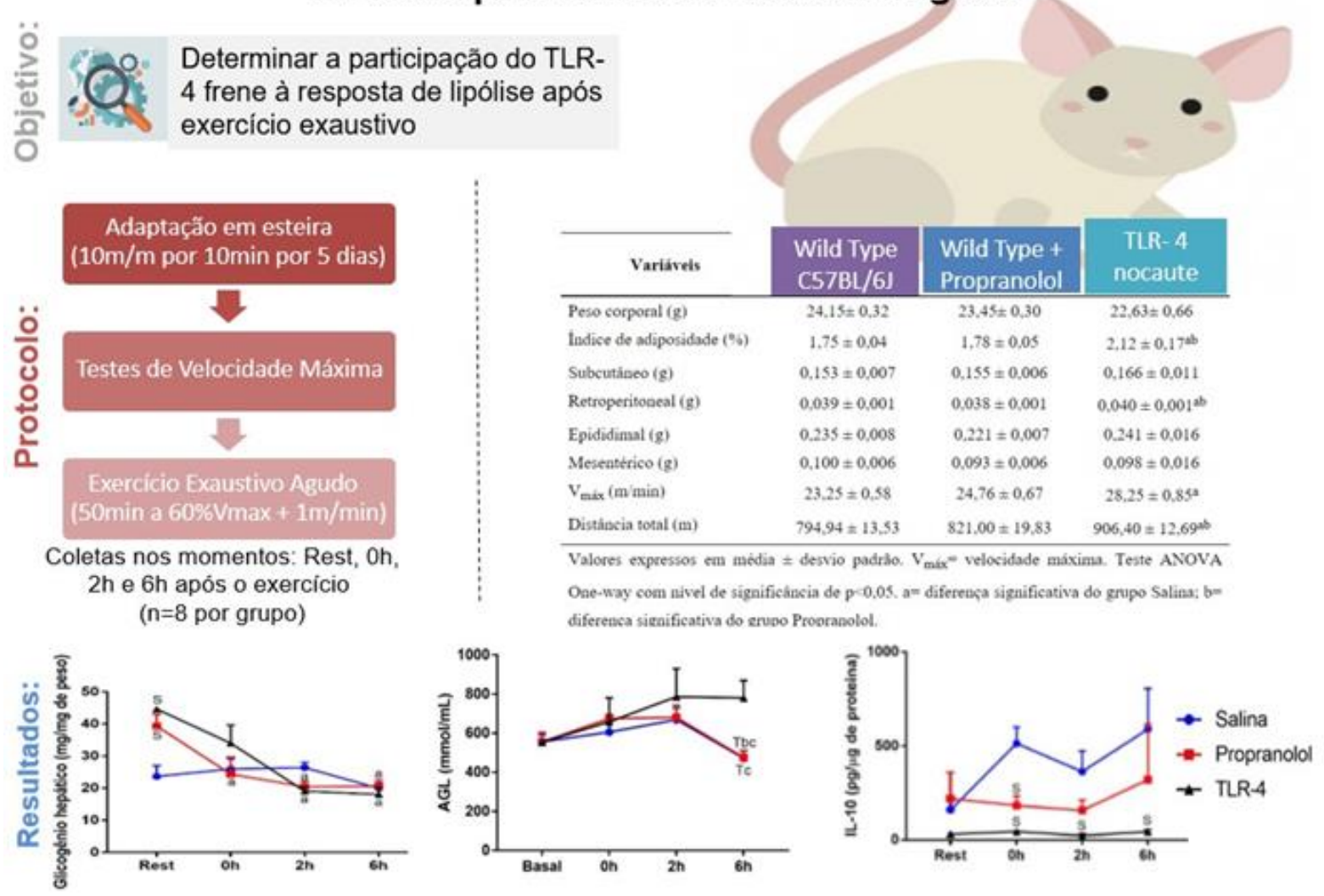
Capacidade de produção de força muscular e comportamento sedentário de crianças e adolescentes em tratamento oncológico: um estudo descritivo

Santo $\mathrm{BCR}^{1 *}$, Cardoso LA ${ }^{1}$, Freitas CLR ${ }^{1}$

${ }^{1}$ Grupo de Pesquisa em Exercício Clínico (GPEC), Universidade Federal de Santa Catarina, Florianópolis, SC, Brasil

*barbaracarlin8@gmail.com

Introdução: O câncer infanto-juvenil refere-se à propagação rápida e desordenada das células, ocorrendo em qualquer parte do organismo. Embora apresente uma taxa de sobrevivência significativa ( $70 \%)$, os efeitos colaterais provocados pela intensidade das abordagens com quimioterapia e radioterapia são problemáticos. O aumento do comportamento sedentário, a diminuição nos níveis de atividade física e da capacidade de produção de força muscular durante e após o tratamento são alguns efeitos colaterais já apontados na literatura. Até o presente momento, não foram identificadas pesquisas que busquem investigar e relacionar a produção de força muscular e o comportamento sedentário desta população. Objetivo: O objetivo geral deste estudo é avaliar a capacidade de produção de força e comportamento sedentário em crianças e adolescentes em tratamento oncológico. Métodos: A amostra será composta por pacientes com idade entre 4-15 anos, em tratamento oncológico em um hospital da grande Florianópolis (SC). Os prontuários médicos serão utilizados para caracterizar os participantes. Serão mensuradas as variáveis antropométricas Peso (balança digital) e Estatura (estadiômetro portátil). O comportamento sedentário será avaliado através de um questionário referente a exposição em tempo médio utilizando telas, em dias típicos da semana e fins de semana. A força muscular isométrica dos flexores e extensores de cotovelo e joelho será avaliada por um dinamômetro manual (microFET2 HHD). Resultados esperados: A partir deste estudo, objetiva-se compreender as adaptações musculares decorrentes da doença e do tratamento, bem como identificar a mudança dos hábitos relacionados a atividade física da população oncológica infantojuvenil. Através dos resultados, espera-se oferecer um diagnóstico enfatizando a importância de os pacientes oncológicos apresentarem um estilo de vida ativo, a fim de minimizar os efeitos do tratamento e melhorar a sua qualidade de vida. Almejamos, futuramente, desenvolver um projeto de extensão universitário que proponha intervenções com atividades físicas orientadas e adequadas direcionadas a essa população no hospital.

Palavras-chave: força muscular; exercício físico; crianças e adolescentes; câncer. 


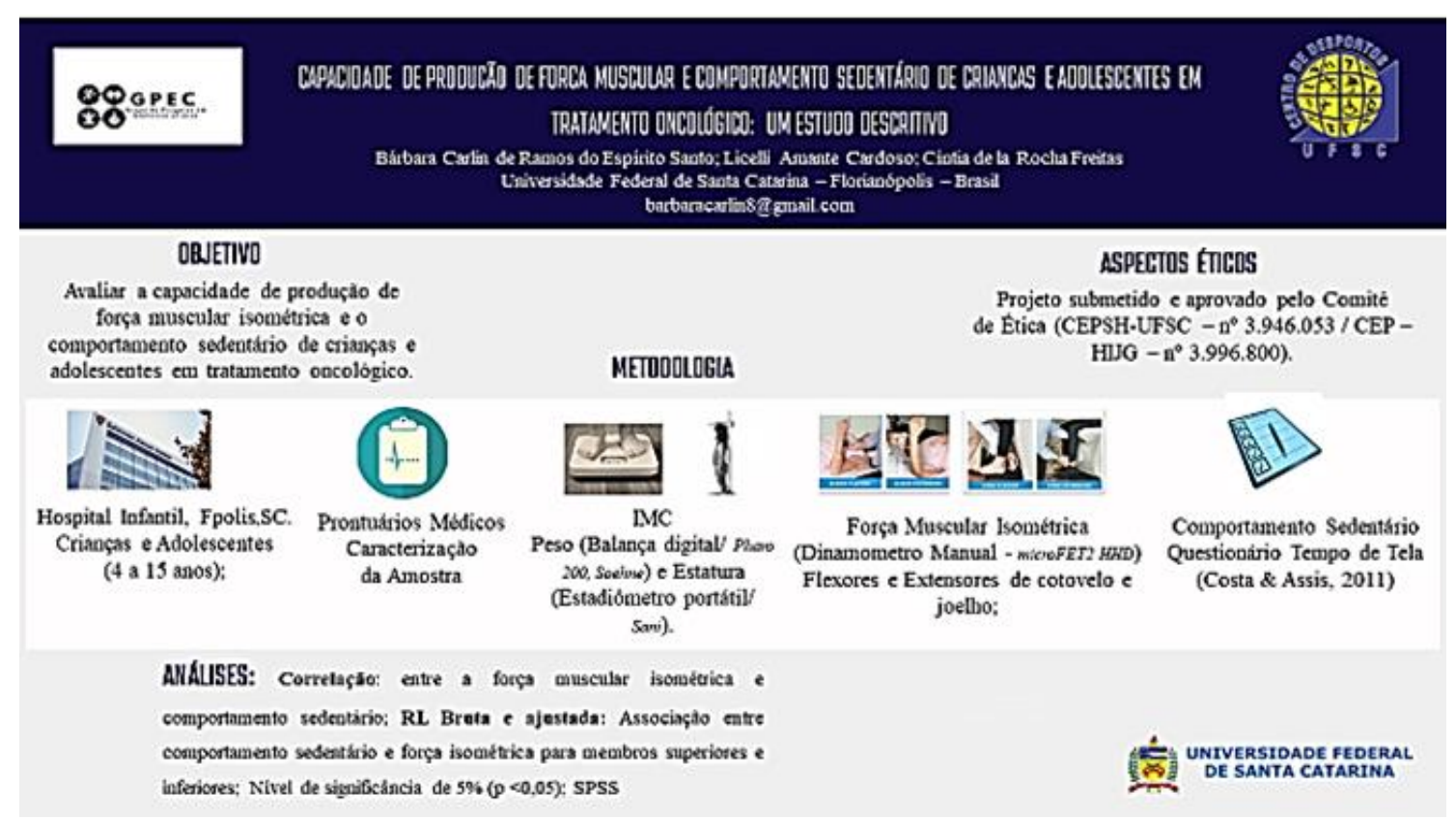

Treino resistido periodizado previne a atrofia e perda de força muscular causadas pela quimioterapia em camundongos

*Nunes $\mathrm{JHC}^{1,2}$, Cella PS ${ }^{1,2}$, Búçu $\mathrm{IP}^{1,2}$, Deminice $\mathrm{R}^{1,2}$

${ }^{1}$ Universidade Estadual de Londrina, Paraná, Brasil (UEL)

${ }^{2}$ Laboratório de Bioquímica do Exercício (LABEX)

*jonathanhenriquep@hotmail.com

Introdução: Guidelines recentes recomendam que pacientes oncológicos realizem exercícios físicos durante seu tratamento. Entretanto, o tratamento quimioterápico promove efeitos adversos severos que podem variar entre os ciclos de infusão, conhecidos com "dias ruins'. Apesar da periodização ser implementada no contexto da aderencia/bem-estar, pouco se sabe sobre o efeito da periodização do treinamento resistido (TR) considerando dias bons e ruins sobre o ganho de força, massa muscular e estresse oxidativo. Objetivo: Analisar os efeitos da periodização do TR considerando os "melhores dias" do ciclo quimioterápico, sobre o ganho de força, massa muscular e estresse oxidativo em camundongos tratados com doxorrubicina (DOX). Métodos: Camundongos Swiss foram divididos aleatoriamente em cinco grupos $(n=14)$ : controle (C), doxorrubicina (DOX), treinados (T), doxorrubicina treinados (DOXT) e doxorrubicina com periodização do treino respeitando os "dias ruins" (DOXTP). A DOX (i.p.) foi aplicada semanalmente num total de $11 \mathrm{mg} / \mathrm{kg}$ em 3 semanas. O TR consistiu de 4 a 8 escaladas, com intensidade progressiva, 3 vezes por semanas, durante 3 semanas. Ao 
final da terceira semana, os animais foram eutanasiados. Resultados: Três semanas de tratamento com DOX promoveram significativa $(p<0,05)$ perda de peso corporal ($14,6 \%)$, atrofia dos músculos EDL (-22,6\%) e sóleo (-27,6\%), perda de força $(-29,6 \%)$ e peroxidação lipidica, MDA (69\%), em comparação ao grupo C. O treinamento resistido preveniu significativamente $(p<0,05)$ a atrofia muscular do EDL, sóleo, perda de força e aumento do GSH/GSSH induzidos pelo tratamento com DOX, somente quando periodizado. Conclusão: O TR, quando periodizado considerando flutuações nos efeitos adversos provocados pelo tratamento quimioterápico, é capaz de prevenir a atrofia e a perda de força muscular. Esta demonstra ser uma variável importante na prescrição de exercício durante o tratamento quimioterápico.

Palavras-chave: treinamento de força; massa muscular; periodização; estresse oxidativo.

Resumo gráfico
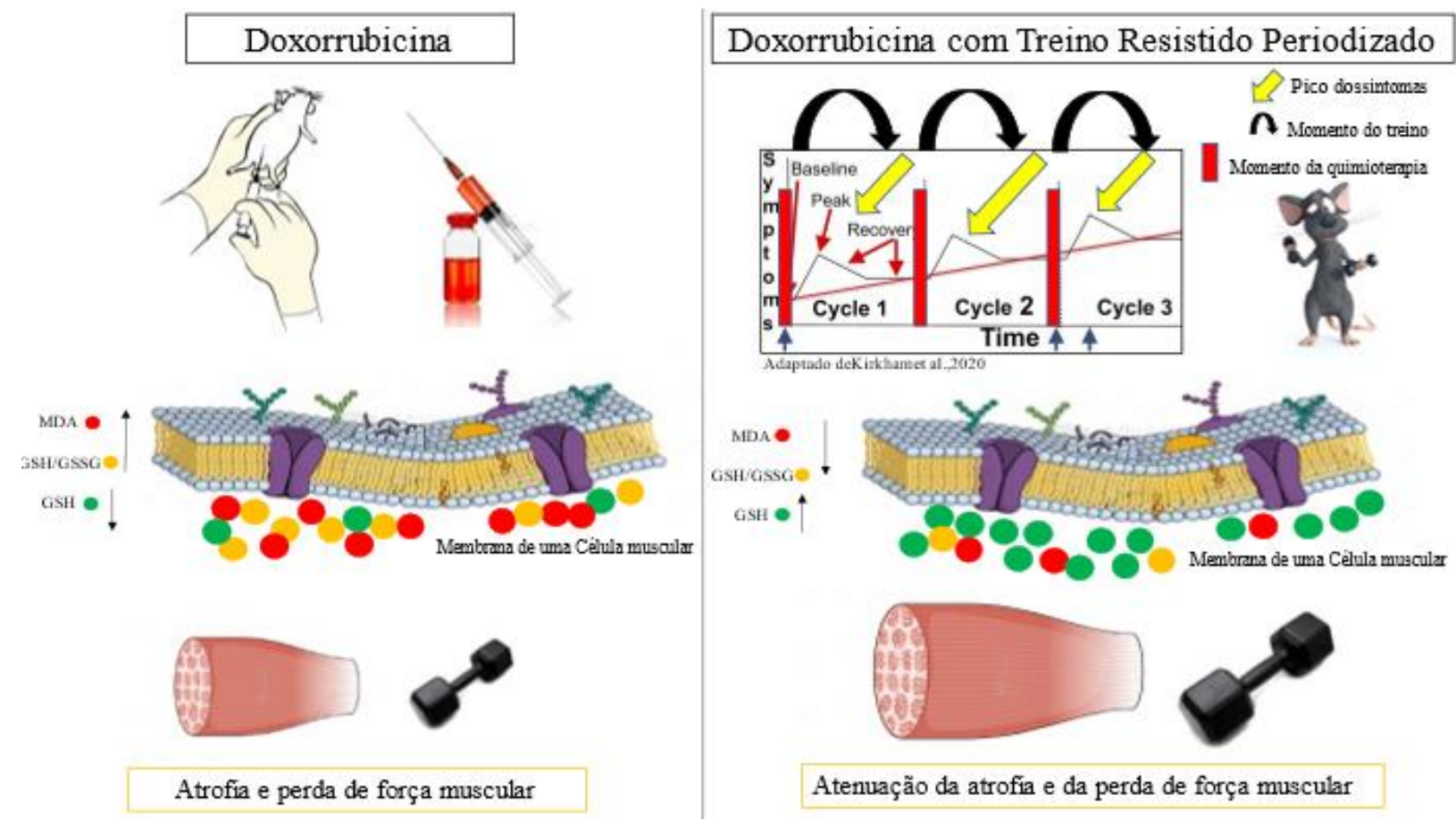
O papel do co-transportador sódio-glicose-2 e do exercício físico na regulação do sistema redox e do complexo inflammasoma em animais com nefropatia diabética

Machado-Junior $\mathrm{PAB}^{1,2 *}$, Anizelli $\mathrm{LB}^{2}$, Kruger $\mathrm{A}^{1}$, Marquese LF${ }^{1}$, Cunha EB ${ }^{1}$, Moraes TP², Pinho RA ${ }^{1,2}$

${ }^{1}$ Laboratório de Bioquímica do Exercício em Saúde, Pontifícia Universidade Católica do Paraná, Curitiba, PR, Brasil

${ }^{2}$ Escola de Medicina, Pontifícia Universidade Católica do Paraná, Curitiba, PR, Brasil

*machadojrpab@gmail.com

Introdução: A importância da resposta inflamatória e do estresse oxidativo na gênese e progressão da nefropatia diabética (ND) tem sido demonstrada em estudos recentes, sendo o complexo inflammasoma NLRP3 um notável regulador desse processo. Abordagens não farmacológicas, a exemplo de dieta e treinamento físico, e farmacológicas, a exemplo dos inibidores do co-transportador sódio-glicose-2 (iSGLT2), constituem importantes pilares para o tratamento da ND; apesar disso, os efeitos dessas terapias de forma combinada sobre os parâmetros de estresse oxidativo, o complexo NLRP3 e histopatologia ainda não são completamente elucidados na literatura. Objetivo: Avaliar o papel do exercício físico e do co-transportador sódio-glicose-2 sobre a regulação do sistema redox e do complexo NLRP3 em animais expostos à ND. Métodos: Camundongos serão randomicamente divididos em 8 grupos: (I) SHAM, (II) ND, (III) SHAM + iSGLT2, (IV) SHAM + treinamento físico, (V) SHAM + iSGLT2 + treinamento físico, (VI) ND + iSGLT2, (VII) ND + treinamento físico, (VIII) ND + iSGLT2 + treinamento físico. A ND será induzida através da associação de dieta hipercalórica e dose única de estreptozotocina. Após 13 semanas, os animais receberão iSGLT2 (Empaglifozina $35 \mathrm{mg} / \mathrm{kg}$ ) ou água destilada, associado ou não a um programa de treinamento físico de intensidade intermediária. Parâmetros clínicos (glicemia plasmática, consumo hídrico, calórico e ganho de peso) serão avaliados semanalmente, e parâmetros funcionais (taxa de filtração glomerular, cleareance de creatinina e albuminúria) serão avaliados trimestralmente. Após 30 semanas de acompanhamento, os animais serão eutanasiados para obtenção de amostras renais e avaliação dos parâmetros histológicos e moleculares. Valores de $p<0,05$ denotarão significância estatística. Resultados esperados: Espera-se que essa combinação seja capaz de retardar a progressão da nefropatia diabética de forma mais eficaz que essas terapias em formas isoladas, por meio da atenuação da resposta inflamatória e do estresse oxidativo.

Palavras-chave: Estresse oxidativo; inflamação; exercício físico; nefropatia diabética. 

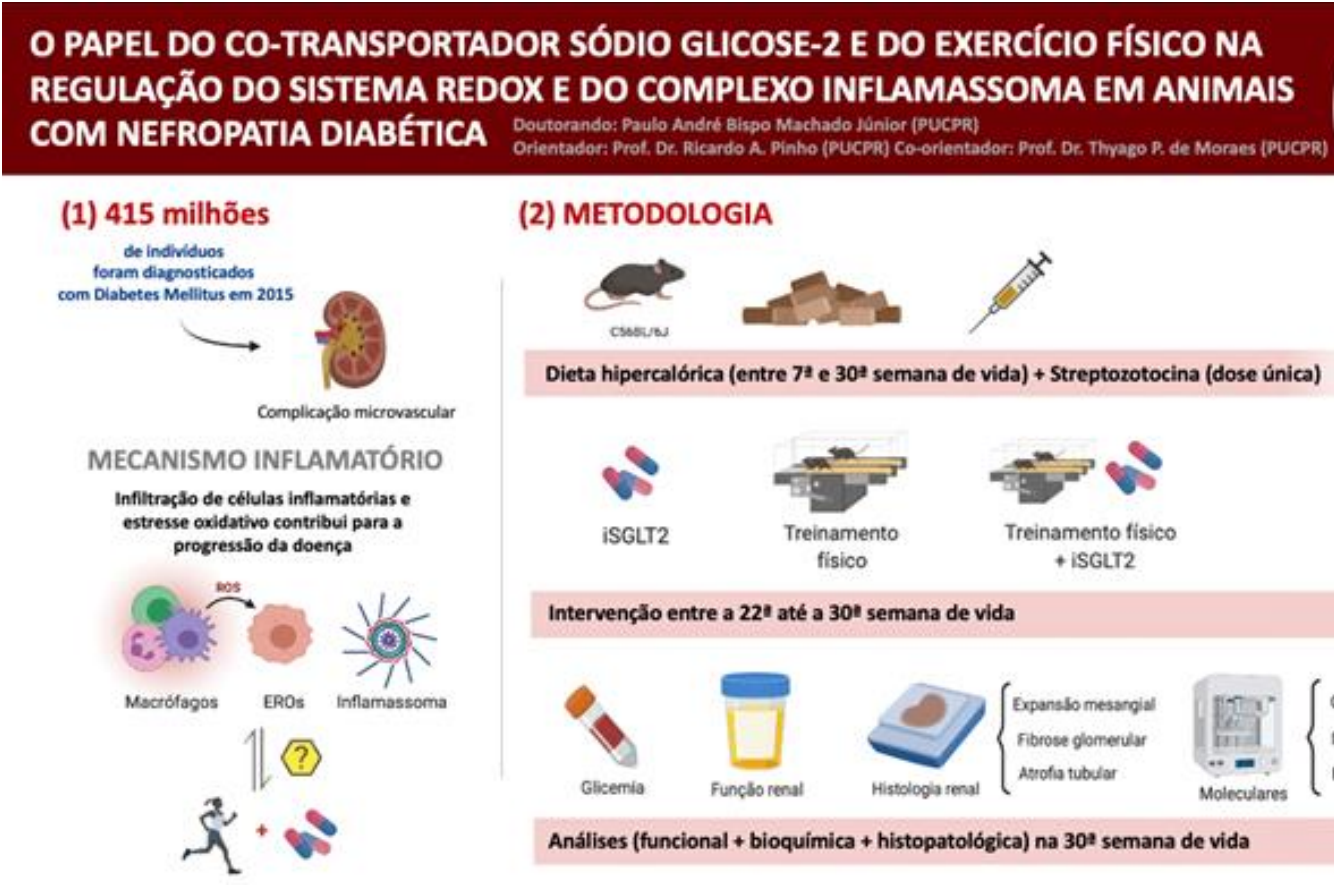

(2) METODOLOGIA

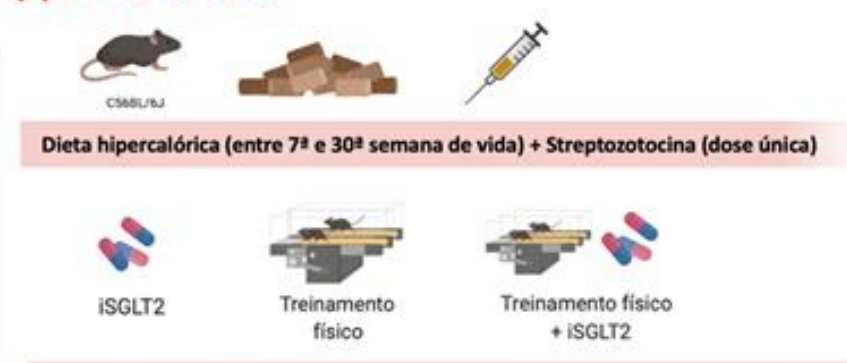

Intervençăo entre a 221 até a 30 s semana de vida

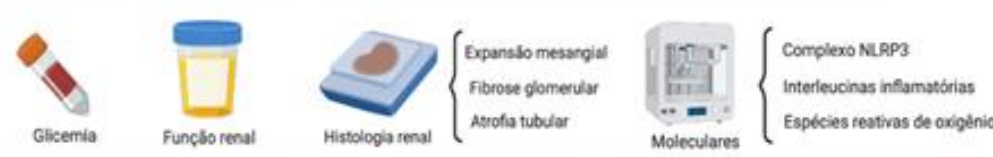

Análises (funcional + bioquimica + histopatológica) na $30^{2}$ semana de vida

Receptor ativado por proliferador de peroxissomo gama (PPARg) modula o imunofenótipo, mas não o perfil anti-inflamatório de macrófagos de camundongos obesos exercitados

Silveira $\mathrm{LS}^{1,2 *}$, Biondo $\mathrm{LA}^{2}$, Teixeira $\mathrm{AAS}^{2}$, Lima Junior $\mathrm{EA}^{2}$, Castoldi $\mathrm{A}^{3}$, Câmara $\mathrm{Nos}^{3}$, Festuccia $\mathrm{WT}^{4}$, Rosa-Neto $\mathrm{JC}^{2}$, Lira FS ${ }^{1}$

${ }^{1}$ Exercise and Immunometabolism Research Group, Postgraduation Program in Movement Sciences, Department of Physical Education, Universidade Estadual Paulista (UNESP), Presidente Prudente, SP, Brazil

${ }^{2}$ Department of Cell and Developmental Biology, Institute of Biomedical Sciences, Universidade de São Paulo (USP), SP, Brazil

${ }^{3}$ Department of Immunology, Institute of Biomedical Sciences, Universidade de São Paulo (USP), SP, Brazil

${ }^{4}$ Department of Physiology and Biophysics, Institute of Biomedical Sciences, Universidade de São Paulo (USP), SP, Brazil

*Ioreana.silveira@usp.br

Introdução: O treinamento aeróbico moderado (TAM) é uma terapia para pacientes com doenças inflamatórias crônicas de baixo grau devido à resposta anti-inflamatória mediada por células do sistema imunológico. O receptor ativado por proliferador de peroxissomo gama (PPARg) regula a polarização M1 (pró-inflamatória) e M2 (antiinflamatória) e o imunometabolismo de macrófagos. Nesse contexto, o presente estudo procurou esclarecer se a deleção condicional do PPARg nos macrófagos teria efeito sobre o papel anti-inflamatório do TAM. Métodos: Para testar esta hipótese, foram 
utilizadas duas linhagens de camundongos: com deleção do PPARg em macrófagos $(\mathrm{KO})$ e animais controle (CTRL). Cada genótipo foi alimentado com dieta hiperlipídica e subdividido em 1) sedentário (HF) e 2) treinamento aeróbico moderado (HFT). O protocolo experimental durou 12 semanas, sendo quatro semanas de dieta apenas mais oito semanas de dieta com TAM (5 vezes/semana, 50-60 minutos/dia a 60\% da velocidade máxima). Análises na morfologia e conteúdo de citocinas do tecido adiposo subcutâneo (TAS), expressão gênica e produção de citocinas por macrófagos peritoneais e imunofenotipagem dos macrófagos do TAS e peritoneais. Resultados: Animais $\mathrm{KO}$ foram mais propensos a hipertrofia do TAS, embora apenas a IL1b $(p=$ $0,0049)$ tenha sido maior em comparação aos valores observados em animais CTRL. Macrófagos peritoneais de animais KO exibiram um aumento no TNFa ( $p=0,0008)$, IL1b ( $p=0,0017)$ e IL-6 ( $p<0,0001)$ após estimulação com lipopolissacarídeos (LPS). Embora o marcador M1 CD86 não tenha sido atenuado com o treino, animais KO expressaram menos citocinas proinflamatórias no TAS. Já em macrófagos peritoneais estimulados com LPS, apesar da atenuação do marcador M2 CD206 ( $p<0,001)$ em KO, o TAM modulou a produção de citocinas em de ambos os genótipos, reduzindo citocinas proinflamatórias como TNFa ( $p=0,0002)$ e IL6 ( $p<0,0001)$. Conclusão: A deleção do PPARg não inibiu o efeito anti-inflamatório mediado pelo exercício, ressaltando a importância do exercício na modulação da inflamação.

Palavras-chave: tecido adiposo, citocinas, sistema imunológico, treinamento aeróbio moderado, fator transcricional.

\section{Fonte financiadora: FAPESP, CAPES}

Resumo gráfico

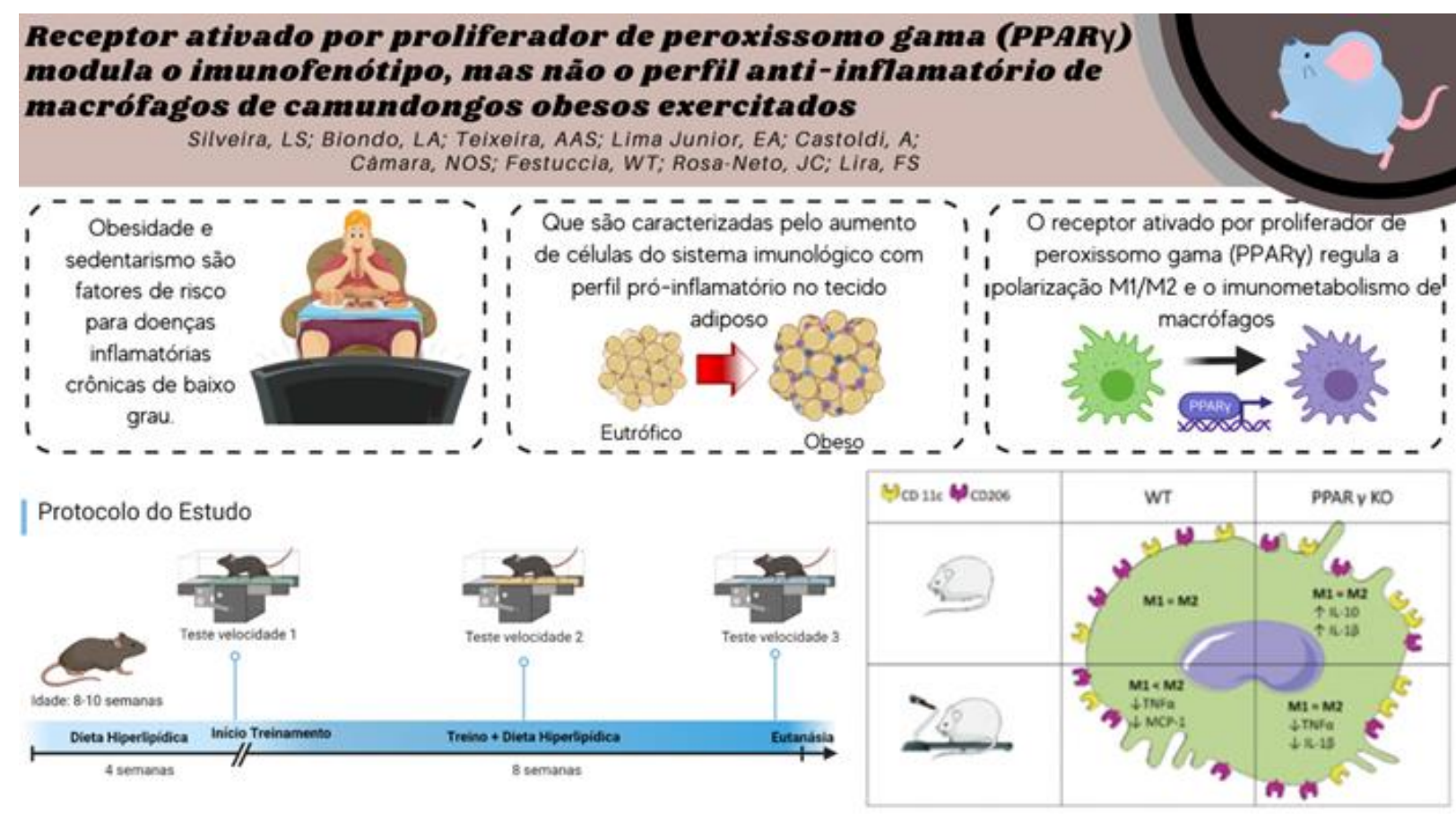

